\title{
The impacts of biomass burning activities on convective systems over the Maritime Continent
}

\author{
Hsiang-He Lee ${ }^{1, \mathrm{a}}$ and Chien Wang ${ }^{1,2, \mathrm{~b}}$ \\ ${ }^{1}$ Center for Environmental Sensing and Modeling, Singapore-MIT Alliance for Research and Technology, Singapore \\ ${ }^{2}$ Center for Global Change Science, Massachusetts Institute of Technology, Cambridge, MA, USA \\ anow at: Atmospheric, Earth, and Energy Division, Lawrence Livermore National Laboratory, Livermore, CA, USA \\ b now at: Laboratoire d'Aerologie/CNRS/University of Toulouse, Toulouse, France
}

Correspondence: Hsiang-He Lee (lee1061@1lnl.gov)

Received: 6 July 2019 - Discussion started: 21 August 2019

Revised: 17 January 2020 - Accepted: 29 January 2020 - Published: 2 March 2020

\begin{abstract}
Convective precipitation associated with Sumatra squall lines and diurnal rainfall over Borneo is an important weather feature of the Maritime Continent in Southeast Asia. Over the past few decades, biomass burning activities have been widespread during summertime over this region, producing massive fire aerosols. These additional aerosols, when brought into the atmosphere, besides influencing the local radiation budget through directly scattering and absorbing sunlight, can also act as cloud condensation nuclei or ice nuclei to alter convective clouds and precipitation over the Maritime Continent via so-called aerosol indirect effects. Based on 4-month simulations with or without biomass burning aerosols, conducted using the Weather Research and Forecasting model coupled with a chemistry module (WRFChem), we have investigated the aerosol-cloud interactions associated with biomass burning aerosols over the Maritime Continent. Results from selected cases of convective events have specifically shown the significant impact of fire aerosols on weak convections by their increasing of the quantities of hydrometeors and rainfall in both the Sumatra and Borneo regions. Statistical analysis over the fire season also suggests that fire aerosols have impacts on the nocturnal convections associated with the local anticyclonic circulation in western Borneo and weaken nocturnal rainfall intensity by about $9 \%$. Such an effect is likely to have come from the near-surface heating due to absorbing aerosols emitted from fires, which could weaken land breezes and thus the convergence of anticyclonic circulation.
\end{abstract}

\section{Introduction}

Biomass burning in Southeast Asia has become a serious environmental and societal issue in the past decade due to its impact on the local economy, air quality, and public health (Miettinen et al., 2011; Kunii et al., 2002; Frankenberg et al., 2005; Crippa et al., 2016; Lee et al., 2018). Abundant aerosols emitted from such fires not only cause environmental issues but also affect regional weather and climate through the direct and indirect effects of biomass burning aerosols (Grandey et al., 2016; Hodzic and Duvel, 2017; Jeong and Wang, 2010; Ramanathan and Carmichael, 2008; Taylor, 2010; Tosca et al., 2013). Carbonaceous compounds such as black carbon (BC) in biomass burning aerosols can reduce sunlight through both absorption and scattering to warm the atmosphere while cooling the Earth's surface (Fujii et al., 2014; Andreae and Gelencsér, 2006; Satheesh and Ramanathan, 2000; Ramanathan et al., 2001). Besides these direct effects, biomass burning aerosols can act as cloud condensation nuclei or ice nuclei to alter cloud microphysical structures and thus cloud radiation. Such "indirect effects" of these aerosols on the climate are even more complicated due to various cloud and meteorological conditions (Sekiguchi et al., 2003; Lin et al., 2013; Wu et al., 2013; Grandey et al., 2016; Ramanathan et al., 2001; Wang, 2004).

For the Maritime Continent in Southeast Asia, convective precipitation associated with the so-called Sumatra squall lines (SSL) and diurnal rainfall over Borneo is an important weather feature (Lo and Orton, 2016; Ichikawa and Yasunari, 2006; Koh and Teo, 2009; Yi and Lim, 2006; $\mathrm{Wu}$ et al., 2009). Convections of SSL are initially formed 
in the northwestern side of Sumatra by the prevailing sea breezes from Indian Ocean and the Sumatran mountain range and then propagate over the Malacca Strait, affecting the Malay Peninsula. Lo and Orton (2016) analyzed 22-year (1988 to 2009) ground-based Doppler radar data and identified a total of 1337 squall lines in Singapore. They found that these events with the diurnal cycle of rainfall most often occur during either the summer monsoon season (JuneSeptember) or the inter-monsoon periods (April-May and October-November). Singapore, for example, typically experiences about 6-7 squall lines per month during these periods. Oki and Musiake (1994) analyzed the seasonal and diurnal cycles of precipitation using rain gauge data and showed that large-scale low-level winds are a critical modulating factor in the diurnal cycle of convective rainfall over Borneo and the general reason for land-sea contrast behind convective rainfall over the Maritime Continent. Furthermore, Ichikawa and Yasunari (2006) used 5 years of Tropical Rainfall Measuring Mission (TRMM) precipitation radar (PR) data to investigate the role of the low-level prevailing wind in modulating the diurnal cycle of rainfall over Borneo. They found that the diurnal cycle is associated with intraseasonal variability in the large-scale circulation pattern, with regimes associated with either low-level easterlies or westerlies over the island.

Interestingly, frequent biomass burning activities coincide with vigorous convective systems over the Maritime Continent, especially during the summer monsoon season (June-September) and could thus produce aerosols to affect convections in the region. Rosenfeld (1999) analyzed TRMM data and hypothesized that abundant biomass burning aerosols could practically shut off warm rain processes in tropical convective clouds. Compared to the adjacent tropical clouds in the cleaner air, clouds encountering smoke could grow to higher altitudes with rain suppressed, hypothetically due to the reduction of coalescence efficiency of smaller cloud drops into raindrops. Recently, using the Weather Research and Forecasting model coupled with a chemistry module (WRF-Chem), Ge et al. (2014) have studied the direct and semi-direct radiative effects of biomass burning aerosols over the Maritime Continent and found the radiative effect of biomass burning aerosols could alter planetary boundary layer (PBL) height, local winds (including sea breeze), and cloud cover. However, the relatively coarse resolution $(27 \mathrm{~km})$ adopted in their simulation would not be able to reveal more details about how biomass burning aerosols affect convective clouds through modifying cloud microphysics processes. In contrast, Hodzic and Duvel (2017) have conducted a $40 \mathrm{~d}$ simulation using WRFChem with a convection-permitting scale $(4 \mathrm{~km})$ to study the fire aerosol-convection interaction during boreal summer in 2009 near the central Borneo mountainous region. Their result suggests that modifications of the cloud microphysics by biomass burning aerosols could reduce shallow precipitation in the afternoon and lead to a warm PBL anomaly at sunset, all leading to an enforcement of deep convection at night. However, they have also indicated that the radiative processes of moderately absorbing aerosols tend to reduce deep convection over most regions due to local surface cooling and atmosphere warming, which both increase static stability, hence suggesting the complexity of the interaction of biomass burning aerosols and convective clouds over the Maritime Continent.

In this study, we aim to examine and quantify the impacts of biomass burning aerosols on convective systems over two targeted regions for analyses: northern Sumatra and western Borneo over the Maritime Continent. Our focus is not only the change of hydrometeors in the convective clouds but also the change of rainfall amount and intensity in these regions. We firstly describe methodologies adopted in the study, followed by the results and findings from our numerical simulations over the Maritime Continent. We have selected three cases in each study region to perform detailed analyses. In addition, statistical analyses covering the entire modeled fire season for each of these two regions have also been performed to provide more generalized pictures about the effects of fire aerosol on convection. The last section summarizes and concludes our work.

\section{Methodology}

\subsection{Model and emission inventories}

In order to simulate trace gases and particulates interacting with the meteorological fields, the Weather Research and Forecasting model coupled with a chemistry module (WRF-Chem; see Grell et al., 2005) version 3.6.1 is used in this study. Within WRF-Chem, the Regional Acid Deposition Model, version 2 (RADM2), photochemical mechanism (Stockwell et al., 1997) coupled with the Modal Aerosol Dynamics Model for Europe (MADE) and the Secondary Organic Aerosol Model (SORGAM) (Ackermann et al., 1998; Schell et al., 2001) are included to simulate atmospheric chemistry and anthropogenic aerosol evolutions. MADE/SORGAM uses a modal approach to represent the aerosol size distribution and predicts mass and number concentrations of three aerosol modes (Aiken, accumulation, and coarse).

To resolve the convective system over the Maritime Continent in our simulations, two model domains with two-way nesting are designed. Here, Domain $1(431 \times 141$ grid cells $)$ has a resolution of $25 \mathrm{~km}$, while Domain $2(561 \times 591$ grid cells) has a resolution of $5 \mathrm{~km}$ (Fig. 1). Specifically, Domain 1 is positioned to include the tropical Indian Ocean in its western half in order to capture the path of the MaddenJulian Oscillation (MJO) and, at the same time, have a northern boundary constrained at $23^{\circ} \mathrm{N}$ in latitude to avoid potential numerical instability from the terrain of the Tibetan Plateau. Domain 2, which has a finer resolution, is positioned 


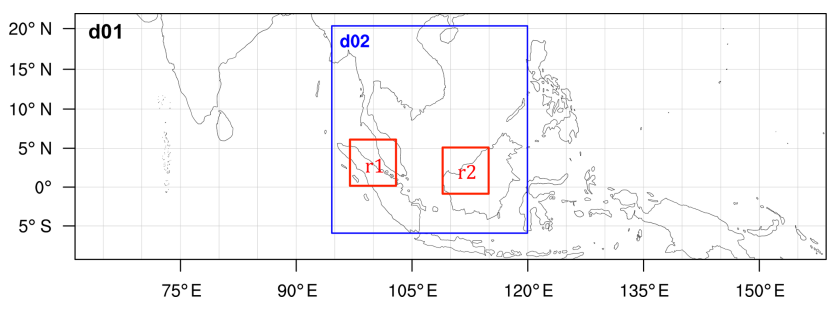

Figure 1. Domain configuration for WRF-Chem simulations. Domain 1 (d01) has a resolution of $25 \mathrm{~km}$, while Domain 2 (d02) has a resolution of $5 \mathrm{~km}$. Two red boxes indicate the two study regions: the Sumatra region (r1) and the Borneo region (r2).

to cover mainland Southeast Asia as well as the islands of Sumatra and Borneo.

National Center for Environment Prediction FiNaL (NCEP-FNL) reanalysis data (National Centers for Environmental Prediction, 2000) are used to provide initial and boundary meteorological conditions and to perform fourdimensional data assimilation (FDDA) to nudge model temperature, water vapor, and zonal and meridional wind speeds above the planetary boundary layer (PBL) for Domain 1 . The time frequency of nudging is every $6 \mathrm{~h}$. The Mellor-YamadaNakanishi-Niino level 2.5 (MYNN) scheme (Nakanishi and Niino, 2009) is chosen to represent the planetary boundary layer in this study. Other physics schemes adopted in the simulations include the Morrison two-moment microphysics scheme (Morrison et al., 2009), the Rapid Radiative Transfer Model for GCMs (RRTMG) longwave and shortwave radiation schemes (Mlawer et al., 1997; Iacono et al., 2008), the Unified Noah land-surface scheme (Tewari et al., 2004), and the Grell-Freitas ensemble cumulus scheme (Grell and Freitas, 2014) (for Domain 1 only). As the main purpose of this study is to reveal fire aerosol-convection interaction through modeling a large quantity of convective systems continually over a relatively long period and taking into account the computational resources available to us, we have adopted a $5 \mathrm{~km}$ horizontal resolution that excludes the cumulus parameterization scheme. Previous studies have shown that a WRF model with a similar resolution without convection parameterization can still capture many critical characteristics of deep convection (Wagner et al., 2018). Our model evaluation, especially through the comparison of modeled results with sounding profiles, has demonstrated the same.

WRF-Chem needs emissions for gaseous and particulate precursors to drive its simulations. For this purpose, we have used the Regional Emission inventory in ASia (REAS) version 2.1 (Kurokawa et al., 2013). REAS includes emissions of most primary air pollutants and greenhouse gases, covering each month from 2000 to 2008. In addition, the Fire INventory from the U.S. National Center for Atmospheric Research (NCAR) version 1.5 (FINNv1.5) (Wiedinmyer et al., 2011) is also used in the study to provide biomass burning emissions. FINNv1.5 separately classifies burning of extra- tropical forest, tropical forest (including peatland), savanna, and grassland. Fire heat fluxes for four different types of fire are prescribed in WRF-Chem to calculate plume height (cf. Table 1 in Freitas et al., 2007). For peatland fire, we have set its heat flux as $4.4 \mathrm{~kW} \mathrm{~m}^{-2}$, which is the same as that of savanna burning and differs from that of the tropical forest burning by $30 \mathrm{~kW} \mathrm{~m}^{-2}$. The plume rise algorithm in WRFChem, specifically modified to improve the representation of tropical peat fire, was described in Lee et al. (2017). It is worth indicating that the heat flux from biomass burning is not incorporated in the thermodynamic equation of the current WRF-Chem model. Note that the current fire emission inventories could underestimate near-surface fire aerosol concentration by ignoring some of the characteristics of smoldering burning as well (Shi et al., 2019).

The default chemical profiles of several species in the lateral boundary condition are higher than their background concentrations in our study region and are thus equivalent for providing additional aerosol sources from boundaries. To prevent this, we have set $\mathrm{NO}, \mathrm{NO}_{2}, \mathrm{SO}_{2}$, and all primary aerosol levels to zero at the lateral boundaries of Domain 1. We have also adjusted the ozone profile used for lateral boundary condition based on the World Meteorological Organization (WMO) Global Atmosphere Watch (GAW) station in Bukit Kototabang, Indonesia (Lee et al., 2019).

\subsection{Numerical experiment design}

Two numerical simulations, both including anthropogenic emissions (mainly fossil fuel emissions) either with and without the biomass burning emissions (hereafter referred to as FFBB and FF, respectively), have been conducted to investigate the impacts of biomass burning aerosols on convective systems over the Maritime Continent through both direct and indirect effects. Our study focuses on the fire season from June to September 2008. Therefore, the simulations start from 1 May 2008 and last for 5 months. The first month is used as a spin-up period. Among the years with available emission data, both emission amount from biomass burning and total precipitation in 2008 approximate their ensemble mean or represent an average condition (Fig. S1 in the Supplement). Nevertheless, interannual variation in biomass burning emissions alongside precipitation in the studied regions do exist (Lee et al., 2017, 2018), and the influence of such variation on the effects of fire aerosol on convection should be addressed in future studies.

\subsection{Analysis methods}

The primary target of this study is the convective systems associated with Sumatra squall lines and diurnal rainfall over Borneo. Thus, our analyses mainly focus on the convections over two specific regions: the Sumatra region (r1 in Fig. 1) and the Borneo region ( $\mathrm{r} 2$ in Fig. 1). The area coverage of the Sumatra region (r1) is from 0 to $6^{\circ} \mathrm{N}$ and 97 to $103^{\circ} \mathrm{E}$, while 
Table 1. The case period of the selected cases in the Sumatra region (r1) and the Borneo region (r2).

\begin{tabular}{ll}
\hline $\begin{array}{l}\text { Case } \\
\text { name }\end{array}$ & Case period \\
\hline r1c1 & $2008 / 08 / 10$ 09:00 UTC-2008/08/11 03:00 UTC \\
r1c2 & $2008 / 08 / 19$ 06:00 UTC-2008/08/20 00:00 UTC \\
r1c3 & $2008 / 09 / 23$ 09:00 UTC-2008/09/24 00:00 UTC \\
r2c1 & $2008 / 08 / 05$ 09:00 UTC-2008/08/06 03:00 UTC \\
r2c2 & $2008 / 09 / 17$ 06:00 UTC-2008/09/17 21:00 UTC \\
r2c3 & $2008 / 09 / 22$ 03:00 UTC-2008/09/23 00:00 UTC \\
\hline
\end{tabular}

Table 2. The fire periods in the two study regions.

\begin{tabular}{ll}
\hline The Sumatra region $(\mathrm{r} 1)$ & The Borneo region $(\mathrm{r} 2)$ \\
\hline 2008/6/10-2008/6/20 & 2008/6/21-2008/6/27 \\
2008/6/25-2008/6/28 & $2008 / 8 / 1-2008 / 8 / 8$ \\
2008/7/4-2008/7/7 & $2008 / 9 / 10-2008 / 9 / 30$ \\
$2008 / 7 / 27-2008 / 8 / 20$ & \\
2008/9/17-2008/9/27 & \\
\hline
\end{tabular}

the area coverage of the Borneo region ( $\mathrm{r} 2)$ is from $1^{\circ} \mathrm{S}$ to $5^{\circ} \mathrm{N}$ and 109 to $115^{\circ} \mathrm{E}$.

To examine the impacts of fire aerosols on cloud formation and rainfall intensity and amount, we have selected three convective systems each for the two focus regions to perform an in-depth case study. We first trace the path of individual convections and focus the analyses on the specific area of each of these convective systems to identify the impacts of fire aerosols. Table 1 shows the selected cases in the Sumatra region ( $\mathrm{r} 1$ ) and the Borneo region ( $\mathrm{r} 2)$. The selected cases are chosen randomly from different fire periods of the two study regions. We did not set any criteria initially when we chose

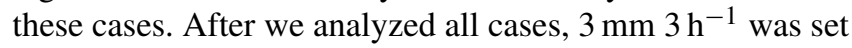
as the threshold to distinguish weak and strong convections.

The consequent analyses are then focused on the fireseason-wise statistics of convections for each study region. Table 2 and Fig. S2 show the fire periods in the two study regions. There is a total of 54 convective systems simulated during the fire periods in the Sumatra region (r1) and 35 convective systems in the Borneo region ( $\mathrm{r} 2$ ).

The statistical quantities used in this study follow Wang (2005) to estimate the mean value over a specific region (e.g., r1 or r2). The cloud area mean quantities are defined as a function of output time step $(t)$ by the following equation:

$$
\bar{c}^{\text {area }}(t)=\frac{1}{N(t)} \sum_{\substack{q>q \min \\ n>n \min }} c(x, y, z, t) .
$$

Here $c$ is a given quantity (e.g., cloud water mass). Equation (1) only applies to the grid points where both the mass concentration $q$ and number concentration $n$ of a hydrome- teor exceed their given minima. The total number of these grid points at a given output time step $t$ is represented by $N(t)$. The cloud area mean quantities are used to present the average quantities of a given variable at a given output time step. Note that the cloud area mean quantities only apply to hydrometeors. For rainfall, the analyzed quantities are spatial averages over a specific area of the convective system for the case study or over the entire study region for longer-term statistical estimates.

\section{Results}

\subsection{Model evaluation}

\subsubsection{Precipitation}

The satellite-retrieved precipitation of the Tropical Rainfall Measuring Mission (TRMM) 3B42 3-hourly (V7) dataset (Huffman et al., 2007) is used in this study to evaluate simulated rainfall. Figure $2 \mathrm{a}$ and $\mathrm{b}$ show the Hovmöller plots of daily TRMM and FFBB precipitation from 1 June 2008 to 30 September 2008, respectively. Compared to the satelliteretrieved data, the model has captured all the major rainfall events in the two analysis regions (Fig. 3). In addition, because of its higher spatial resolution than TRMM, the model produces more light rain events. Nevertheless, as indicated in our previous study (Lee et al., 2017), a wet bias of the model is evident and mainly comes from water vapor nudging in data assimilation (FDDA). As a result, the daily average rainfall in FFBB over the Sumatra region (r1) was $11.05 \pm 5.90 \mathrm{~mm} \mathrm{~d}^{-1}$ from 1 June 2008 to 30 September 2008, higher than that of $7.21 \pm 5.54 \mathrm{~mm} \mathrm{~d}^{-1}$ derived from TRMM retrieval. The wet bias also exists in the modeling results in the Borneo region (r2), where daily average rainfall there is $15.40 \pm 8.49 \mathrm{~mm} \mathrm{~d}^{-1}$ in FFBB and only $9.56 \pm 7.20 \mathrm{~mm} \mathrm{~d}^{-1}$ in TRMM. For the simulated rainfall in FFBB, the temporal correlation with TRMM is 0.44 in the Sumatra region (r1) and 0.64 in the Borneo region (r2).

\subsubsection{Aerosol optical depth (AOD)}

Because of limited ground-based observational data of aerosols, we use Aerosol Optical Depth (AOD) from the level-3 Moderate Resolution Imaging Spectroradiometer (MODIS) gridded atmosphere monthly global joint product (MOD08_M3; https://doi.org/10.5067/MODIS/MOD08_M3.061, last access: February 2020) to evaluate modeled aerosol spatial distribution and relative concentration. Figure 4a shows MODIS monthly AOD in Southeast Asia in September 2008. High AOD occurs in the southern part of Sumatra and the southwestern part of Borneo. Compared to the MODIS retrieval, the modeled AOD in FFBB has a similar spatial distribution but a higher value (Fig. 4b). This is because a high spatiotemporal resolution in our simulation enables 

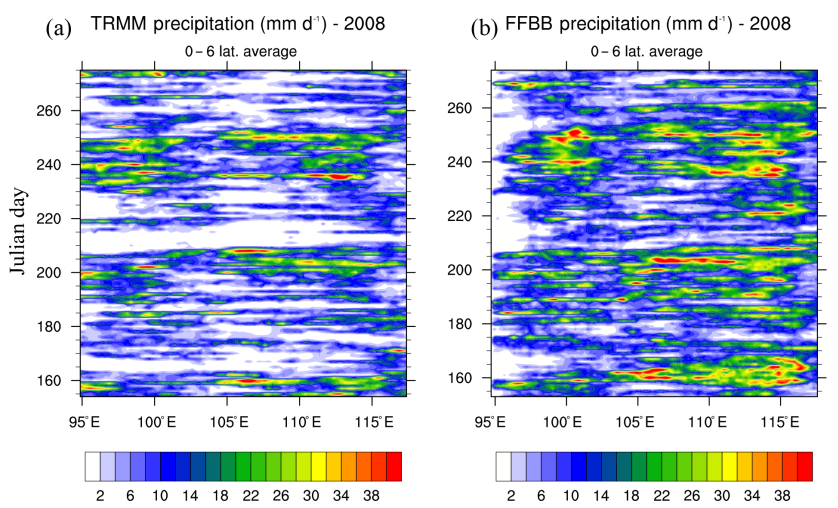

Figure 2. Hovmöller (time versus longitude) plot of daily precipitation ( $\mathrm{mm} \mathrm{d}^{-1}$ ) from 1 June 2008 to 30 September 2008 from the (a) Tropical Rainfall Measuring Mission (TRMM) and (a) FFBB. Latitude average is from 0 to $6^{\circ} \mathrm{N}$.

(a) Rainfall comparison - r1

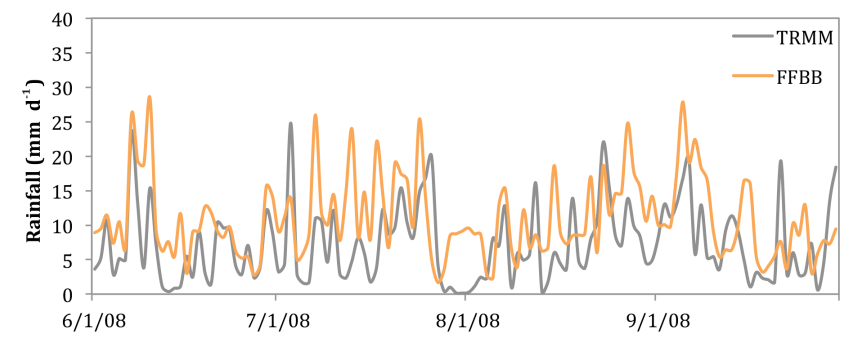

(b) Rainfall comparison - $r 2$

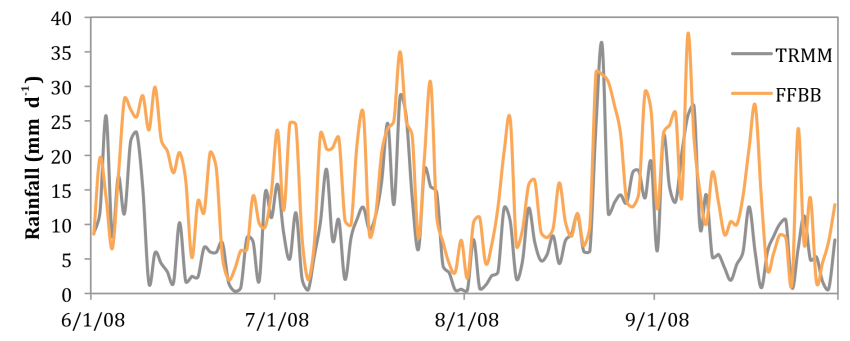

Figure 3. Time series of area-averaged daily rainfall $\left(\mathrm{mm} \mathrm{d}^{-1}\right)$ from the Tropical Rainfall Measuring Mission (TRMM) and FFBB over (a) the Sumatra region (r1) and (b) the Borneo region (r2).

the model to capture episodic fire events better. In contrast, FF simulation produces much lower AOD values than those of MODIS and FFBB, thus suggesting biomass burning aerosols make up a substantial fraction of atmospheric AOD during burning seasons.

\subsubsection{Sounding profiles}

We have used multiple weather sounding profiles measured at Bintulu Airport, Malaysia $\left(3.20^{\circ} \mathrm{N}, 113.03^{\circ} \mathrm{E}\right)$, provided by University of Wyoming (http://weather.uwyo.edu/ upperair/sounding.html, last access: February 2020). An example for detailed summary is a case at 12:00 UTC on 22
September 2008 (Fig. 5a). This sounding provides information about atmospheric state (e.g., vertical distributions of pressure, temperature, wind speed, wind direction, and humidity) coinciding with one of our selected case studies (r2c3) of diurnal convective rainfall in Borneo. Compared to the observed sounding data, the FFBB simulation has produced similar temperature and wind profiles and captured the low-level and high-level wind speeds and wind directions well (Fig. 5a versus 5b). It also predicts several key indexes of convection well: temperature and pressure of the lifted condensation level (LCL) simulated in FFBB are $296.2 \mathrm{~K}$ and $955 \mathrm{hPa}$, respectively, which are close to the values of $296.2 \mathrm{~K}$ in temperature and $960.7 \mathrm{hPa}$ in pressure derived from the observed sounding data. The model predicts $3049 \mathrm{~J}$ of convective available potential energy (CAPE), while $2031 \mathrm{~J}$ of CAPE is estimated in the observed sounding data. Besides this 22 September 2008 case, the model has also captured major features of observed profiles for all the other cases selected in our analyses shown in Figs. S3-S7 in the Supplement.

\subsubsection{Cloud vertical structure}

The Cloud-Aerosol Lidar and Infrared Pathfinder Satellite Observation (CALIPSO) provides information about the vertical structure of clouds on its path around the globe (https://www-calipso.larc.nasa.gov/products/lidar/ browse_images/production/, last access: February 2020), including that of one of our cases (r2c3) of diurnal convective rainfall in Borneo on 22 September 2008 (Fig. 6a). For this case, CALIPSO shows the vertical structure of a convective system over Borneo along with high $\mathrm{PM}_{2.5}$ concentration near the surface (yellowish color near the surface), implying a potential impact of biomass burning aerosols on convective clouds. It can be seen that the FFBB simulations capture the vertical structure of convective clouds as well as the nearsurface aerosol layers well, including their vertical extension (Fig. 6c versus 6a). With the comparison of FF simulation, we are able to identify the biomass burning origin of these aerosols near the surface. It is worth indicating that we have compared more than 50 modeled convections during the fire season and within the simulation domains. However, the others captured by CALIPSO are either not among the selected cases or are mostly out of our analyzed domains, so we did not discuss them further here.

\subsection{Analyses of selected cases in two study regions}

\subsubsection{The Sumatra region $(r 1)$}

The three selected cases in $\mathrm{r} 1$ in the Sumatra region $(\mathrm{r} 1 \mathrm{c} 1$, r1c2 and r1c3) all occurred in the afternoon (14:00 or 17:00 local time, LT) and lasted less than $24 \mathrm{~h}$ (Table 1). The sounding profiles of the three cases are quite similar to the environmental profiles (Figs. S3-S5). Most fire aerosols in this 
(a) MODIS monthly AOD - 2008

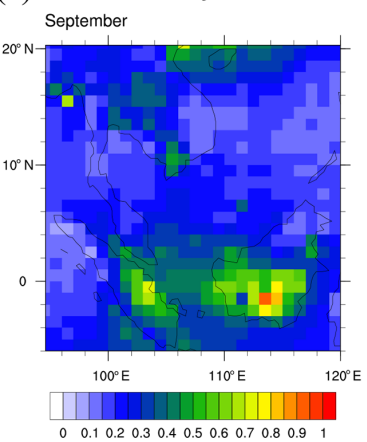

(b) FFBB monthly AOD - 2008 September

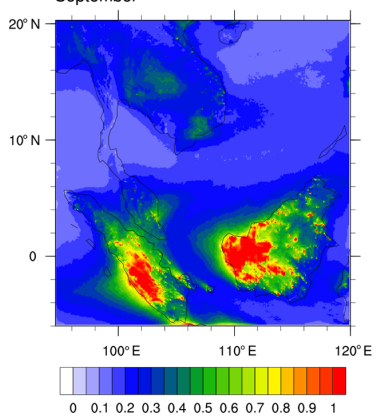

(c) FF monthly AOD - 2008 September

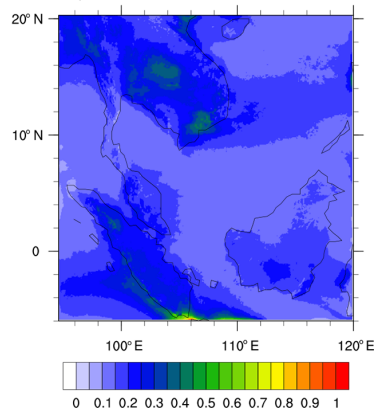

Figure 4. Monthly aerosol optical depth (AOD) in September 2008 from (a) Moderate Resolution Imaging Spectroradiometer (MODIS), (b) FFBB, and (c) FF.

(a)

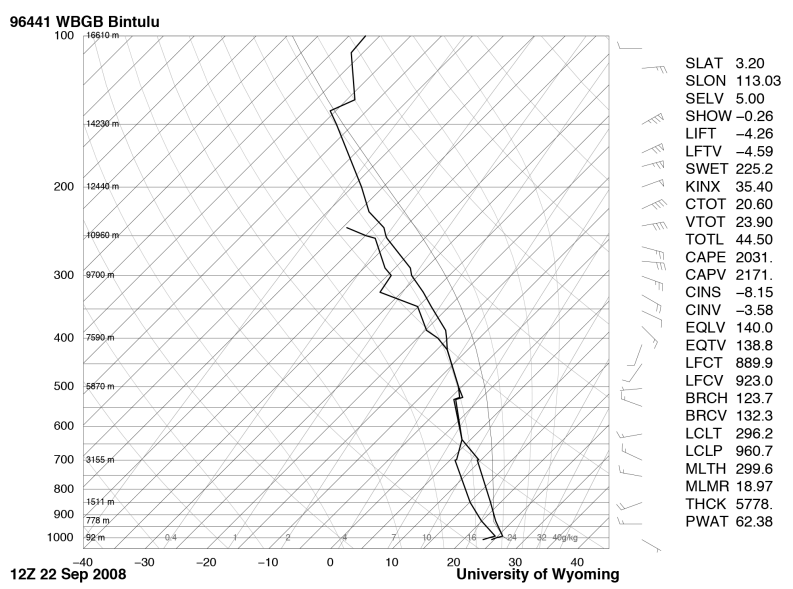

(b)

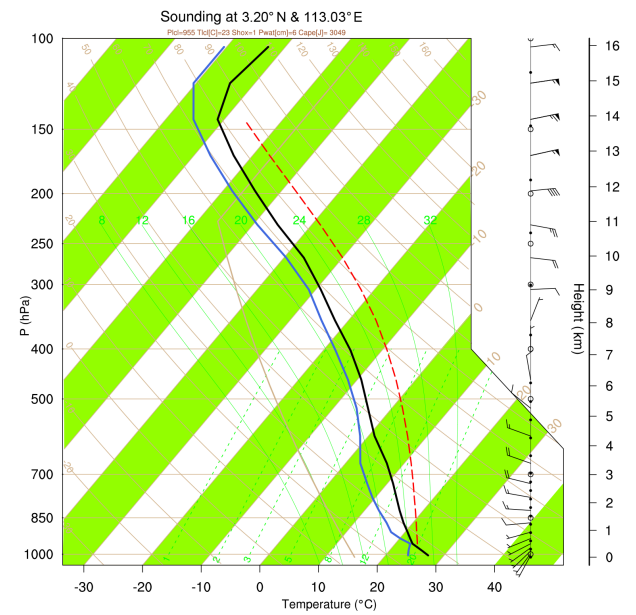

Figure 5. (a) Sounding profile observed at Bintulu Airport, Malaysia $\left(3.20^{\circ} \mathrm{N}, 113.03^{\circ} \mathrm{E}\right)$ at $12: 00 \mathrm{UTC}$ on 22 September 2008. (b) Modeled sounding profile in FFBB at the same location and time as (a). study region were initially emitted from central and southern Sumatra then transported along with southwesterly winds to encounter convections in northern Sumatra. Compared to the result of FF, $\mathrm{PM}_{2.5}$ concentration in FFBB can be 6-12 times higher in the Sumatra region (r1) in these selected cases (Fig. 7).

Aerosols from biomass burning in FFBB add 2-3 times more cloud droplet number concentration and 8\%-20\% higher cloud water mass compared to the results in FF (Table 2). The mean radius of cloud droplets in FFBB is about 6-7 $\mu \mathrm{m}$, clearly smaller than that in FF $(10-11 \mu \mathrm{m})$. Smaller cloud droplets in FFBB reduce the efficiency of autoconversion and further decrease rainwater mass and raindrop number concentration. Hence, raindrop number concentration in FFBB is $40 \%-50 \%$ lower than that in FF among our selected cases in r1 (Table 3). However, besides autoconversion, rainwater mass is also affected by other microphysics processes. Larger raindrops combining with smaller cloud droplets in FFBB can enhance the efficiency of cloud droplet collection by rain (and thus increase rainwater mass) but cause no change to the number of raindrops, possibly compensating for the decrease in rainwater mass resulting from a lowered autoconversion. Overall, rainwater mass decreases $15 \%$ in the case of $\mathrm{r} 1 \mathrm{c} 2$ and $10 \%$ in the case of r1c3. Compared to the cases of $\mathrm{r} 1 \mathrm{c} 2$ and $\mathrm{r} 1 \mathrm{c} 3$, the case of $\mathrm{r} 1 \mathrm{c} 1$ is a relatively weak convective system based on a threshold of $\sim 3 \mathrm{~mm}$ $3 \mathrm{~h}^{-1}$ of the averaged rainfall in FF (Table 4). After introducing fire aerosols, the mass concentration of snow and graupel in this case increases $62 \%$ and $48 \%$, respectively. Melting snow and graupel in the lower atmosphere results in a significant increase in rainwater mass concentration of $49 \%$. Thus, total hydrometeor mass is increased by $36 \%$ in FFBB from that in FF. Our result is consistent with that of Lin et al. (2006), which suggested that biomass burning aerosols could invigorate convection and then increase precipitation based on satellite observations. The aerosol invigoration effect refers to a hypothetical process wherein an increasing number of smaller cloud droplets due to higher aerosol concentration would reduce the efficiency of raindrop formation 

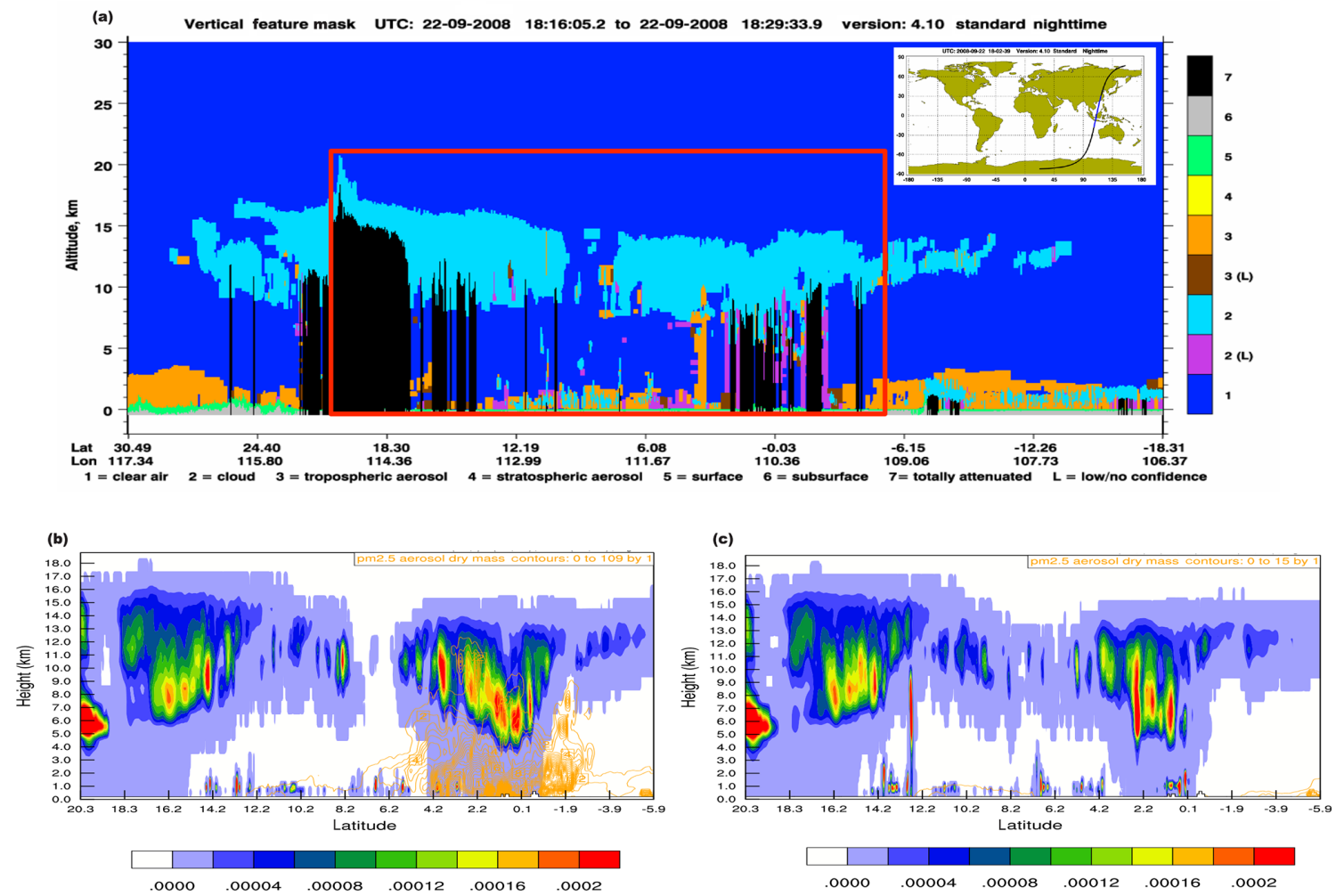

Figure 6. (a) The vertical structure of cloud retrieved from the Cloud-Aerosol Lidar and Infrared Pathfinder Satellite Observation (CALIPSO) on 22 September 2008. (b-c) The sum of simulated hydrometeor mixing ratio (shaded; $\mathrm{kg} \mathrm{kg}^{-1}$ ) and $\mathrm{PM}_{2.5}$ concentration (contour; $\mu \mathrm{g} \mathrm{m}^{-3}$ ) in FFBB and FF, respectively. The profile domains of (b) and (c) correspond to the red rectangle in (a).

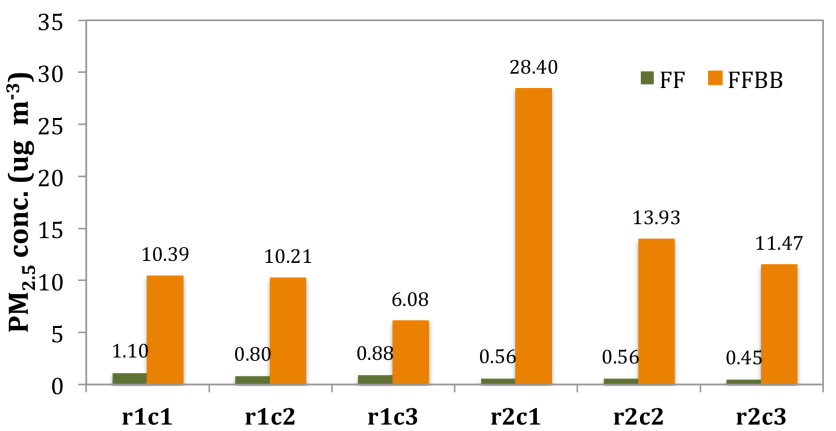

Figure 7. The mean $\mathrm{PM}_{2.5}$ concentration $\left(\mu \mathrm{g} \mathrm{m}^{-3}\right)$ in $\mathrm{FF}$ and FFBB for selected cases in the Sumatra region (r1) and the Borneo region (r2).

from self-collection among cloud droplets and thus further slowdown the loss of these small droplets via being collected by larger raindrops, allowing more of them to reach high altitudes, where they would eventually be collected by ice particles through riming, causing a release of latent heat to enhance the updraft (Rosenfeld et al., 2008). For tropical regions with high humidity, additional aerosols may also lead to the warm-phase invigoration due to the consequent enhancement in total condensed water quantity and thus latent heat release (Wang, 2005; Fan et al., 2018). Note that the "aerosol-aware" microphysics scheme in WRF-Chem only applies to the warm cloud process (Morrison et al., 2005, 2009); therefore, ice nucleation is only parameterized using ambient temperature, regardless of the aerosol concentration. In our model configuration, fire aerosol can still affect the ice process, however, this is through a cloud condensation nuclei effect rather than serving directly as ice nuclei.

In the FF simulations, the convective system in the case of $\mathrm{r} 1 \mathrm{c} 2$ and $\mathrm{r} 1 \mathrm{c} 3$ is stronger than the system in the case of $\mathrm{r} 1 \mathrm{c} 1$ and the average rainfall of $\mathrm{r} 1 \mathrm{c} 2$ and $\mathrm{r} 1 \mathrm{c} 3$ are both higher than the rainfall of r1c1 (Table 4). Adding fire aerosols in FFBB does not substantially change the average rainfall in $\mathrm{r} 1 \mathrm{c} 2$ and r1c3 ( $+3 \%$ and $-8 \%$, respectively; Table 4$)$. However, in the relatively weak convective system of $\mathrm{r} 1 \mathrm{c} 1$, adding fire aerosols significantly increases the mean rainfall amount by

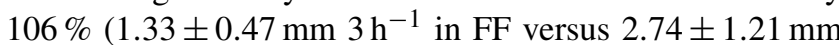
$3 \mathrm{~h}^{-1}$ in FFBB).

\subsubsection{The Borneo region ( $\mathrm{r} 2)$}

The three selected cases in $\mathrm{r} 2(\mathrm{r} 2 \mathrm{c} 1, \mathrm{r} 2 \mathrm{c} 2$, and $\mathrm{r} 2 \mathrm{c} 3)$ also occurred during the summer monsoon season when active biomass burning events existed in western Borneo. In these cases, fire aerosols were transported to the north and north- 
Table 3. The mean differences in percentage of FFBB to FF (i.e., (FFBB - FF) $/ F F \times 100 \%$ ) for each selected case over the main convection area in the Sumatra region (r1) and the Borneo region (r2). $Q_{\mathrm{c}}, Q_{\mathrm{i}}, Q_{\mathrm{r}}, Q_{\mathrm{s}}$, and $Q_{\mathrm{g}}$ represent cloud, ice, rain, snow, and graupel mass concentrations, respectively. $Q_{\mathrm{nc}}, Q_{\mathrm{ni}}, Q_{\mathrm{nr}}, Q_{\mathrm{ns}}$, and $Q_{\mathrm{ng}}$ are the number concentration for each hydrometeor.

\begin{tabular}{lrrrrrrrrrr}
\hline Case & $Q_{\mathrm{c}}$ & $Q_{\mathrm{i}}$ & $Q_{\mathrm{r}}$ & $Q_{\mathrm{s}}$ & $Q_{\mathrm{g}}$ & $Q_{\mathrm{nc}}$ & $Q_{\mathrm{ni}}$ & $Q_{\mathrm{nr}}$ & $Q_{\mathrm{ns}}$ & $Q_{\mathrm{ng}}$ \\
\hline $\mathrm{r} 1 \mathrm{c} 1$ & $8 \%$ & $27 \%$ & $49 \%$ & $62 \%$ & $48 \%$ & $248 \%$ & $55 \%$ & $-41 \%$ & $33 \%$ & $39 \%$ \\
$\mathrm{r} 1 \mathrm{c} 2$ & $20 \%$ & $-6 \%$ & $-15 \%$ & $-25 \%$ & $1 \%$ & $349 \%$ & $-1 \%$ & $-45 \%$ & $-11 \%$ & $-6 \%$ \\
$\mathrm{r} 1 \mathrm{c} 3$ & $18 \%$ & $10 \%$ & $-10 \%$ & $3 \%$ & $5 \%$ & $311 \%$ & $4 \%$ & $-50 \%$ & $11 \%$ & $-6 \%$ \\
$\mathrm{r} 2 \mathrm{c} 1$ & $27 \%$ & $1 \%$ & $-6 \%$ & $-5 \%$ & $-4 \%$ & $703 \%$ & $3 \%$ & $-59 \%$ & $4 \%$ & $-5 \%$ \\
$\mathrm{r} 2 \mathrm{c} 2$ & $22 \%$ & $10 \%$ & $64 \%$ & $69 \%$ & $58 \%$ & $337 \%$ & $24 \%$ & $-32 \%$ & $17 \%$ & $57 \%$ \\
$\mathrm{r} 3 \mathrm{c} 3$ & $8 \%$ & $10 \%$ & $19 \%$ & $60 \%$ & $-2 \%$ & $409 \%$ & $-5 \%$ & $-66 \%$ & $8 \%$ & $-12 \%$ \\
\hline
\end{tabular}

Table 4. The averaged precipitation $\left(\mathrm{mm} 3 \mathrm{~h}^{-1}\right)$ of FFBB and FF for each selected case over the main convection area in the Sumatra region ( $\mathrm{r} 1$ ) and the Borneo region ( $\mathrm{r} 2)$. Parentheses in the third column show the difference in percentage between FFBB and FF (i.e., $(\mathrm{FFBB}-\mathrm{FF}) / \mathrm{FF} \times 100 \%)$.

\begin{tabular}{lrr}
\hline Case & FF & FFBB \\
\hline r1c1 & $1.33 \pm 0.47$ & $2.74 \pm 1.21(+106 \%)$ \\
r1c2 & $2.97 \pm 1.42$ & $3.05 \pm 1.49(+3 \%)$ \\
r1c3 & $4.32 \pm 1.84$ & $3.98 \pm 2.18(-8 \%)$ \\
r2c1 & $3.73 \pm 2.64$ & $3.07 \pm 1.21(-18 \%)$ \\
r2c2 & $1.88 \pm 0.53$ & $3.97 \pm 1.47(+111 \%)$ \\
r3c3 & $0.54 \pm 0.53$ & $1.10 \pm 1.02(+103 \%)$ \\
\hline
\end{tabular}

east by the southeasterly and southwesterly winds. Because of the proximity of fire emissions, the $\mathrm{PM}_{2.5}$ concentration in FFBB could be 24 times higher than that in FF in the Borneo region (r2) in these selected cases (Fig. 7).

The modeled results demonstrate the substantial impacts of fire aerosols on both ambient aerosol concentration and cloud droplet number concentration. $\mathrm{PM}_{2.5}$ concentration in FFBB is drastically higher than that in FF, with the highest increase appearing in the case of $\mathrm{r} 2 \mathrm{c} 1$ at $4940 \%$, more than double the values of r2c2 (2402\%) and r2c3 (2422\%). The increase in cloud droplet number concentration in the case of $\mathrm{r} 2 \mathrm{c} 1(703 \%)$ is also substantially higher than those in $\mathrm{r} 2 \mathrm{c} 2(337 \%)$ and $\mathrm{r} 2 \mathrm{c} 3(409 \%)$ (Table 2$)$. The mean radius of cloud droplets in FFBB is about $6-7 \mu \mathrm{m}$, which is significantly smaller than that in FF $(10-11 \mu \mathrm{m})$. The mean cloud droplet radii in FF and FFBB in $\mathrm{r} 2$ are similar to the results in $\mathrm{r} 1$. On the other hand, the increase in cloud water mass due to fire aerosols is not so dramatic in all these cases, only about $8 \%-27 \%$ higher than that in the FF simulations (Table 3). As discussed above, rain number concentration in FFBB over the Borneo region (r2) is lower than that in FF, similar to the cases in r1, likely due to the low efficiency of autoconversion induced by the presence of a large quantity of smaller cloud droplets. Rainwater mass of FFBB in the r $2 \mathrm{c} 1$ case is decreased by about $6 \%$ due to fire aerosols, which is similar to the results in the $\mathrm{r} 1 \mathrm{c} 2$ and $\mathrm{r} 1 \mathrm{c} 3$ cases over the
Sumatra region (Table 3). However, interestingly, rainwater and snow mass are both increased in FFBB by $64 \%$ and $69 \%$ in $\mathrm{r} 2 \mathrm{c} 2$ and by $19 \%$ and $60 \%$ in r2c3, respectively (Table 3 ). The cases of $\mathrm{r} 2 \mathrm{c} 2$ and $\mathrm{r} 2 \mathrm{c} 3$ are relatively weak convective systems, similar to the case of r1c1. Again, this is based on

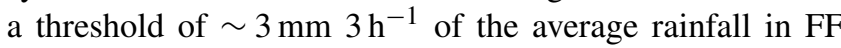
(Table 4). Our results show that fire aerosols have substantial impacts on cold cloud processes in weak convective systems. Overall, total hydrometeor mass concentration in FFBB has increased $47 \%$ in $\mathrm{r} 2 \mathrm{c} 2$ and $13 \%$ in $\mathrm{r} 2 \mathrm{c} 3$.

The changes of rainfall amount due to fire aerosols in $r 2$ are similar to the cases in $\mathrm{r} 1$. For the strong convection case of $\mathrm{r} 2 \mathrm{c} 1$, adding fire aerosols in the FFBB simulation decreases the total rainfall amount by $18 \%$. However, in the weak convection cases of $\mathrm{r} 2 \mathrm{c} 2$ and $\mathrm{r} 2 \mathrm{c} 3$, adding fire aerosols would double the rainfall amount (Table 4). Compared to the results in FF, rainfall intensity is persistently higher in FFBB during the convection life cycle in those weak convection cases. In particular, nighttime rainfall intensity in FFBB is much higher than the rainfall intensity in FF. Therefore, as shown by our results, fire aerosols appear to have more substantial impacts on the quantities of hydrometeors and rainfall of the weak convection cases in both the Sumatra region (r1) and the Borneo region (r2).

Our results show that fire aerosols tend to invigorate weak convection but suppress deep convection in both the Sumatra region ( $\mathrm{r} 1)$ and the Borneo region ( $\mathrm{r} 2)$. As mentioned before, increasing the number of smaller cloud droplets due to higher aerosol concentration resulting from fire would reduce the efficiency of raindrop formation through the warm rain processes, thus allowing more cloud droplets reaching high altitudes to be eventually collected by ice particles through riming, causing the release of latent heat to invigorate the updraft while enhancing precipitation through melting of fallen ice particles (Wang, 2005). These processes appear to be more effective for weak convections than deep convections and were in fact well simulated in the former cases. The results are also consistent with some previous observationbased studies (Jiang et al., 2018; Zhao et al., 2018). Jiang et al. (2018) and Zhao et al. (2018) both concluded that an increase in fire aerosols generally reduces cloud optical thick- 
ness of deep convection, while Zhao et al. (2018) further showed that fire aerosols tend to invigorate weak convection for small-to-moderate aerosol loading.

\subsection{Fire season statistics of convections in two study regions}

Statistics covering the entire simulated fire season $(\sim 4$ months) for each study region have been derived to provide trend and tendency information regarding several aspects of the impact of fire aerosols on convections. In our simulations, $\mathrm{PM}_{2.5}$ concentration in FF during the fire periods, which can be regarded as the background value for FFBB simulation before adding fire aerosols, is $1.36 \pm 0.19 \mu \mathrm{g} \mathrm{m}^{-3}$ in $\mathrm{r} 1$ and $0.56 \pm 0.09 \mu \mathrm{g} \mathrm{m}^{-3}$ in $\mathrm{r} 2$. In comparison, $\mathrm{PM}_{2.5}$ concentration in FFBB is $11.37 \pm 10.41 \mu \mathrm{g} \mathrm{m}^{-3}$ in $\mathrm{r} 1$ and $10.07 \pm$ $7.73 \mu \mathrm{g} \mathrm{m}^{-3}$ in $\mathrm{r} 2$. Note that unlike in some other studies where the control simulations use constant aerosol concentrations, fire aerosol concentrations in our simulations can vary in response to changes in fire emissions or aerosol removal by rain scavenging due to precipitation change caused by fire aerosols themselves. Hence, the processes included in our simulations are closer to reality, and the results could better reflect the nature of fire aerosol-convection interaction over the Maritime Continent.

Averaged throughout the entire modeled fire period, cloud water mass $\left(Q_{\mathrm{c}}\right)$, cloud droplet number concentration $\left(Q_{\mathrm{nc}}\right)$, and raindrop number concentration $\left(Q_{\mathrm{nr}}\right)$ in FFBB differ substantially from those in $\mathrm{FF}$, demonstrating the influence of fire aerosols. Figure 8 shows that adding fire aerosols in FFBB would increase $Q_{\mathrm{c}}$ by $14 \%$ and $Q_{\mathrm{nc}}$ by $226 \%$ in $\mathrm{r} 1$ and $Q_{\mathrm{c}}$ by $18 \%$ and $Q_{\mathrm{nc}}$ by $349 \%$ in r2. Another pronounced change in response to adding fire aerosols is a decrease in $Q_{\mathrm{nr}}$ by $44 \%$ in $\mathrm{r} 1$ and $47 \%$ in r2. Although this shows an increase in snow mass $\left(Q_{\mathrm{s}}\right)$ and graupel mass $\left(Q_{\mathrm{g}}\right)$ and a decrease in rainwater mass $\left(Q_{\mathrm{r}}\right)$ after adding fire aerosols, the uncertainty of these hydrometeor changes is large.

In Sect. 3.2, we discussed the significant rainfall increase that occurred in weak convective systems after adding fire aerosols due to the aerosol invigoration effect. On one hand, regardless of the strength of convection, the mean 3-hourly rainfall during the fire periods is $1.06 \pm 0.85 \mathrm{~mm}$ in $\mathrm{FF}$ and $1.09 \pm 0.86 \mathrm{~mm}$ in FFBB over the Sumatra region ( $\mathrm{r} 1)$ and statistically does not change significantly when responding to fire aerosols. The rainfall difference in the Borneo region ( $\mathrm{r} 2)$ between FF and FFBB is also insignificant $(1.32 \pm 1.20 \mathrm{~mm}$

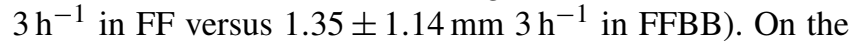
other hand, we have found that the impacts of fire aerosols appear in several other rainfall patterns. For instance, the daily maximum and minimum rainfalls display clear differences between the FFBB and FF simulations, specifically in r2 rather than in r1 (Fig. 9). For r1, the impacts of fire aerosol are reflected in event-wise statistics, e.g., higher event-wise maximum and minimum rainfall intensity in FFBB than in

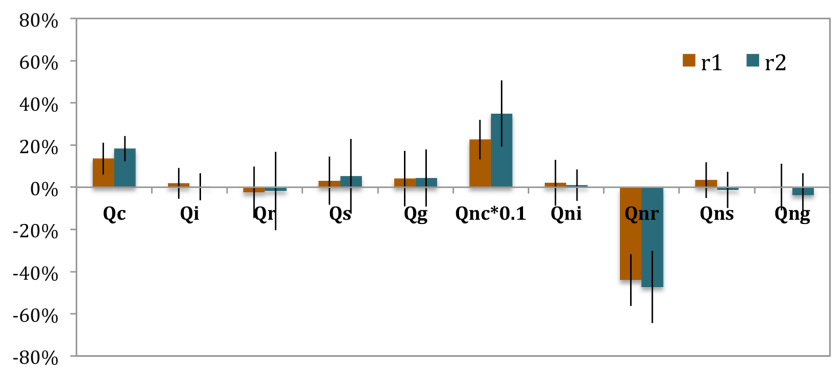

Figure 8. The mean differences in percentage of FFBB to FF (i.e., $(\mathrm{FFBB}-\mathrm{FF}) / \mathrm{FF} \times 100 \%$ ) over all convective cases during the fire periods in the Sumatra region (r1) and the Borneo region (r2). $Q_{\mathrm{c}}$, $Q_{\mathrm{i}}, Q_{\mathrm{r}}, Q_{\mathrm{s}}$, and $Q_{\mathrm{g}}$ represent cloud, ice, rain, snow, and graupel mass concentrations, respectively. $Q_{\mathrm{nc}}, Q_{\mathrm{ni}}, Q_{\mathrm{nr}}, Q_{\mathrm{ns}}$, and $Q_{\mathrm{ng}}$ are the number concentration for each hydrometeor. The error bars represent a single standard deviation.

FF, identified in 30 out of 54 convective events in total. These are mostly weak convective events in $\mathrm{r} 1$. Interestingly, somewhat opposite to the rainfall statistics in $\mathrm{r} 1$, the intensity of event-wise maximum and minimum rainfall in $\mathrm{r} 2$ is higher in $\mathrm{FF}$ than in FFBB. The daily rainfall peak of $3 \mathrm{~h}$ rainfall in $\mathrm{r} 1$ is mostly less than $3 \mathrm{~mm}$; in comparison, one-third of convective events in $\mathrm{r} 2$ have daily maximum $3 \mathrm{~h}$ rainfall exceeding $3 \mathrm{~mm}$ (Fig. 9c), suggesting that the convective systems in $\mathrm{r} 2$ tend to develop stronger than in $\mathrm{r} 1$ and the fire aerosols significantly suppress the maximum rainfall intensity of strong

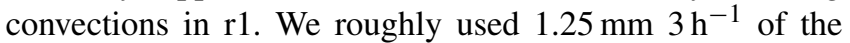
domain-averaged rainfall to classify weak and strong convective systems. We find that the conclusions regarding differences between hydrometers and rainfall in weak systems between the FF and FFBB experiments stay the same and that such differences are still not that significant in both regions (Table S1 and Fig. S8).

We have categorized the maximum rainfall based on its values in the afternoon and at midnight. We find that the heavy maximum rainfalls in $\mathrm{r} 2$ that tend to occur at midnight (Fig. 9c) are associated with the anticyclonic circulation formed in western Borneo induced by southeasterly winds from southern latitudes and turn northeastward along the west coast of Borneo, owing to the terrain of Borneo and sea breeze from the South China Sea. The vortex produced by such a circulation leads to strong updraft and then strong convection. Note that this anticyclonic circulation is different from the Borneo vortex, the latter appears as a persistent feature of the boreal winter climatology and is related to the northeasterly from the South China Sea and cold surge events (Chang et al., 1983, 2005).

The low-level wind pattern of Borneo convections is similar to the westerly regime, especially the weak westerly (WW) regime identified by Ichikawa and Yasunari (2006). According to their analysis, the WW regime tends to occur in boreal summer. Its composites include an anticyclonic feature with the weak wind field over Borneo. The deep convec- 
(a) r1 max. rainfall

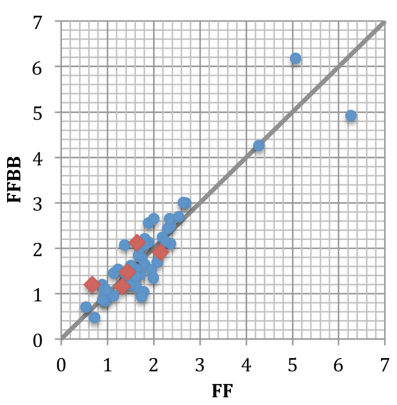

(c) r2 max. rainfall

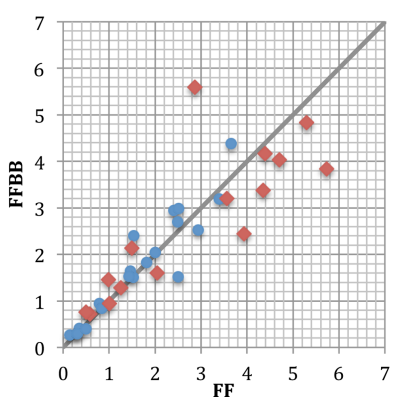

(b) r1 min. rainfall

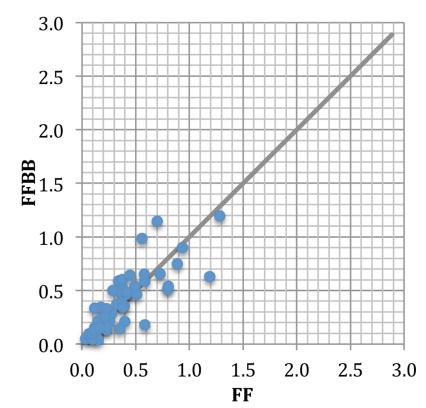

(d) $r 2$ min. rainfall

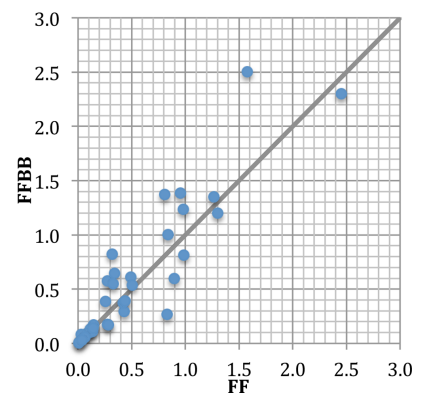

Figure 9. The scatterplots of daily maximum and minimum con-

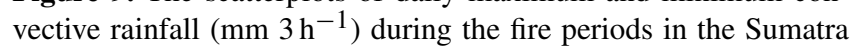
region (r1) and the Borneo region ( $\mathrm{r} 2)$. Red diamonds in (a) and (c) indicate that the maximum convective rainfall is found at midnight or in the early morning.

tive storms developed in the WW regime tend to stay close to the west coast, which is associated with the lower-level convergence enhanced by the prevailing wind and local circulations around that area, resulting in localized rainfall over the offshore region of the west coast. Based on our simulations, the onset of convection occurs in the afternoon over the western mountain range of Borneo. These storms would consequently evolve into widespread shallow storms in the evening over the western part of the island. The maximum rainfall appears on the west coast because of a local westward propagating rainfall system that develops around midnight or in the early morning.

The comparison of the maximum rainfall between $\mathrm{FF}$ and FFBB in Fig. 9 shows that fire aerosols tend to reduce the maximum rainfall, especially for high-intensity rainfall events. In other words, fire aerosols have substantial impacts on the nocturnal convections, which are associated with the local anticyclonic circulation in western Borneo. This effect on nocturnal convections in western Borneo by fire aerosols will be discussed further in the next section.

\subsection{The impact of biomass burning aerosols on nocturnal convections in the Borneo region}

To further analyze the effects of fire aerosols on nocturnal convections, we have categorized convective events into

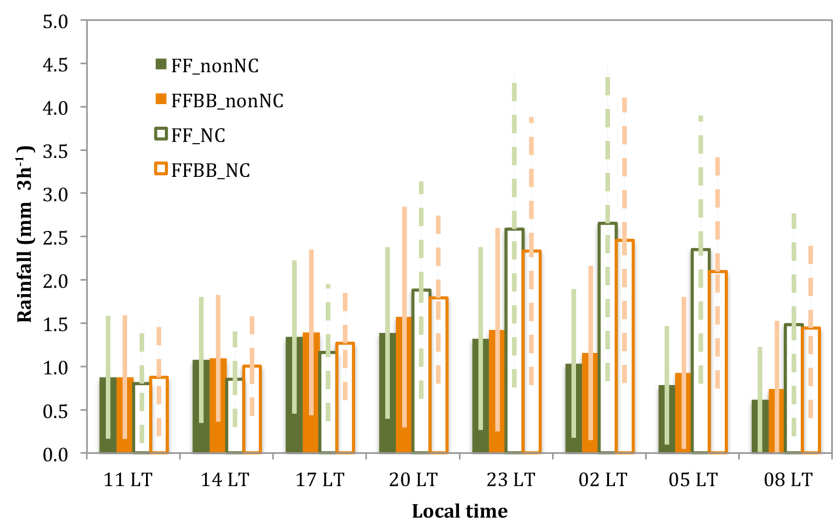

Figure 10. The diurnal time series of rainfall averaged over the Borneo region (r2) for nocturnal convections (NC) and non-nocturnal convections (non-NC) during fire periods in FF and FFBB. The error bars denote the standard deviation of the rainfall.

nocturnal convections (NC) and non-nocturnal convections (non-NC), based on whether the maximum rainfall occurs from midnight to the early morning or from the late afternoon to the evening. Figure 10 shows the diurnal time series of precipitation averaged over the Borneo region ( $\mathrm{r} 2)$ in $\mathrm{FF}$ and FFBB. Again, $3 \mathrm{~h}$ mean rainfalls of nocturnal convections are higher than those of non-nocturnal convections in both simulations and fire aerosols weaken the maximum nocturnal rainfall intensity by about $9 \%$.

Nocturnal convections tend to stay close to the west coast, associated with a lower-level convergence enhanced by the prevailing wind and local circulations that are mainly related to the land breezes from inland western Borneo. The strong convergence near the surface over the offshore region of the west coast causes the weak westerly monsoon windflaws and local land breezes to merge during the nighttime. However, during the fire periods, the daytime absorption of fire aerosols (e.g., black carbon) can cause an atmospheric warming (even without fire-generated heating flux being incorporated in the model). This could increase near-surface air temperature and weaken land breezes and surface convergence. As a result, the nocturnal convections in FFBB cannot develop as strongly as those in FF. On the other hand, both nocturnal and non-nocturnal convections are initiated over the western mountain range under a prevailing wind of the sea breezes from the South China Sea. The increases in nearsurface temperature owing to the fire aerosols can enhance this prevailing wind from the ocean and thus lead to a higher convective rainfall in FFBB during the onset stage of the nocturnal convections as well as non-nocturnal convections. Figure 11 illustrates the sea breeze increase in FFBB during the daytime (20:00 LT) and the land breeze decrease in FFBB during the nighttime (02:00 LT). The times of 20:00 LT and 02:00 LT are chosen here because of the peak of difference.

Diurnal evolution of vertical profiles clearly indicates that mass mixing ratio of total hydrometeors, temperature, 
(a)

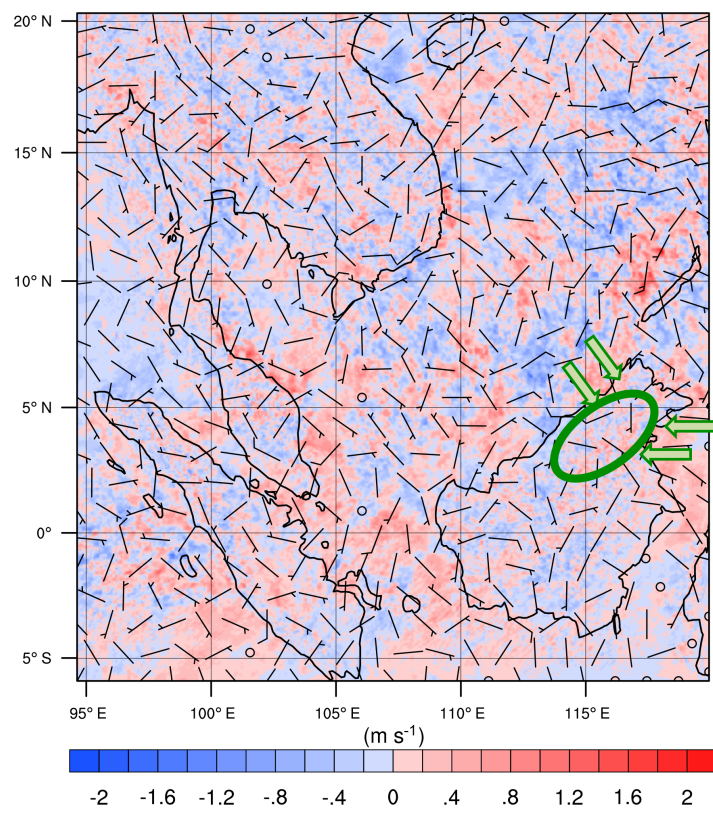

(b)

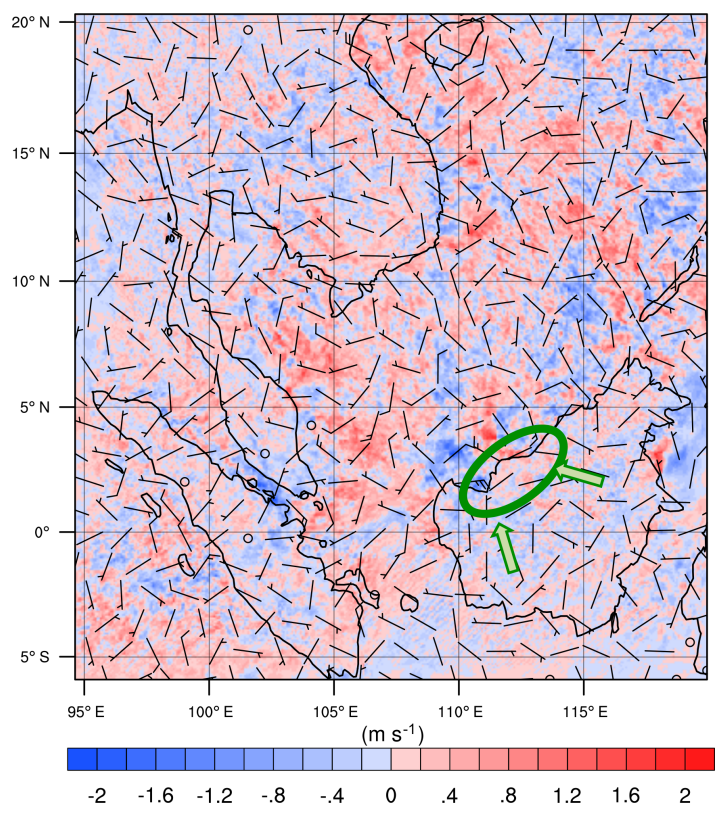

Figure 11. The mean wind field differences of FFBB and FF (FFBB-FF) at (a) 20:00 LT for non-nocturnal cases and (b) 02:00 LT for nocturnal cases in the Borneo region ( $\mathrm{r} 2$ ). The green circle indicates the location in which convections occurred. The green arrows show the mean flow of sea breeze in (a) and land breeze in (b). The magnitude of wind barbs is 10 times higher than the real value.

and vertical velocity differ in both daytime and nighttime between FF and FFBB for those nocturnal convections (Fig. 12). The differences of near-surface temperature between FF and FFBB are more pronounced during the period after sunset (Fig. 12d). The differences of near-surface temperature mainly happen over land, and the higher nearsurface temperature in FFBB weakens the land breezes and near-surface convergence along the coast. Starting from late afternoon (about 17:00 LT), vertical velocity increases with time until sunrise the next day in both simulations (Fig. 12e), due to the convergence of the monsoon windflaws and local land breezes during the nighttime, which matches very well with the of mass mixing ratio of total hydrometeors (Fig. 12a and e). Noticeably, the main differences in vertical velocity and hydrometeor mass mixing ratio between FFBB and FF also start to become evident in the evening. Because of the weaker convergence near the surface in FFBB, the differences in vertical velocity at the higher altitude between FFBB and FF peak at nighttime. The temperature increase from aerosol absorption seems small (please note that the direct heating from fire is not included in the WRF fire plume model), but we do see the change of vertical velocity owing to the aerosol heating effect. Based on our analysis, the temperature increase is mainly associated with the thermodynamic perturbation from the absorption of sunlight by fire aerosols. This also seems consistent with the analysis of Zhang et al. (2019). Indeed, should the heat flux generated by fires be incorporated in the model, the warming effects from biomass burning would be much stronger and also persist in a nocturnal time frame.

As a summary, the schematics shown in Fig. 13 illustrate the impact of biomass burning activities on nocturnal convections in the Borneo region. In the daytime, under the prevailing wind of sea breezes from the South China Sea, convections develop over the western mountain range. Because near-surface heating from the absorption of sunlight by fire aerosols could enhance the prevailing wind from the ocean, convective rainfall becomes higher at the onset stage of the nocturnal convections (still during daytime) due to biomass burning activities (Fig. 13b). At nighttime, convection moves to the offshore region of western Borneo. The strong convergences near the surface merge the weak westerly monsoon windflaws with local nighttime land breezes to form an anticyclonic circulation (Fig. 13c). During the fire periods, the daytime near-surface warming by fire aerosols could also further weaken land breezes and surface convergence. Hence, the nocturnal convections during fire events would not develop as strongly as in days without fires (Fig. 13d versus 13c).

\section{Summary}

By comparing WRF-Chem modeling results including or excluding biomass burning emissions (FFBB versus FF), we have identified certain detailed impacts of fire aerosols on convective events within two study regions over the Maritime Continent during a 4-month period (June 2008-September 2008). In total, 54 convective systems in the Sumatra region and 35 convective systems in the Borneo region have been 
(a) Total hydro. mixing ratio $\left(\mathrm{mg} \mathrm{kg}^{-1}\right)$

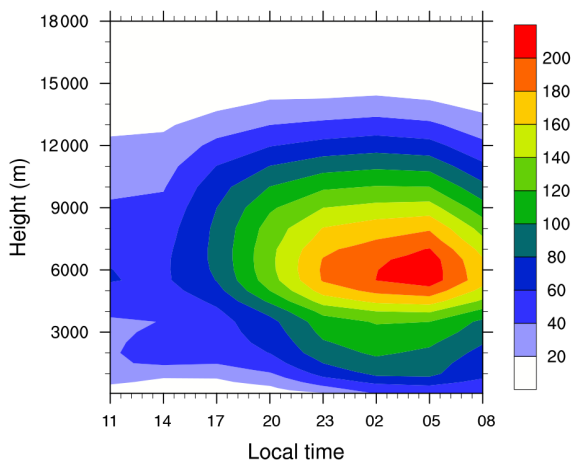

(c) Temperature $\left({ }^{\circ} \mathrm{C}\right)$

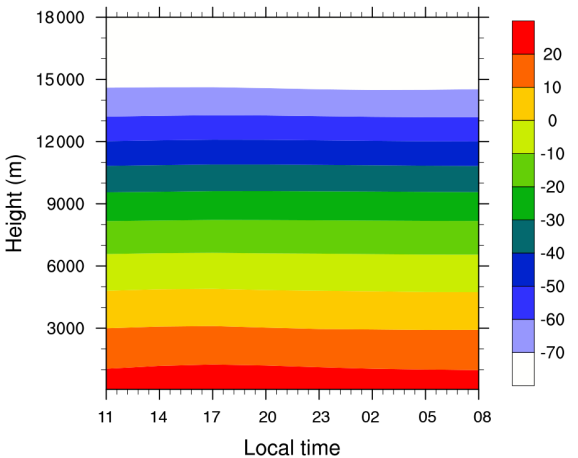

(e) Vertical velocity $\left(\mathrm{m} \mathrm{s}^{-1}\right)$

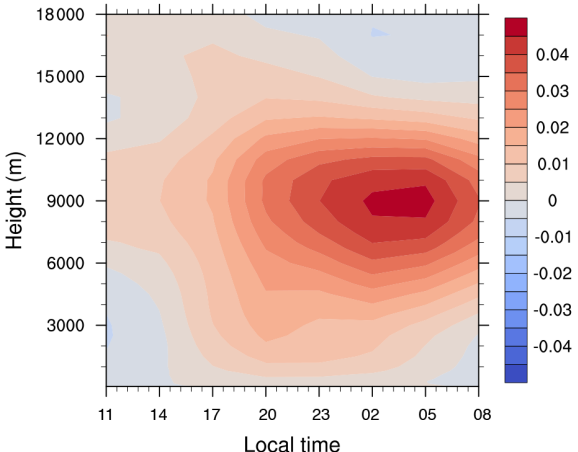

(b) Total hydro. difference $\left(\mathrm{mg} \mathrm{kg}^{-1}\right)$

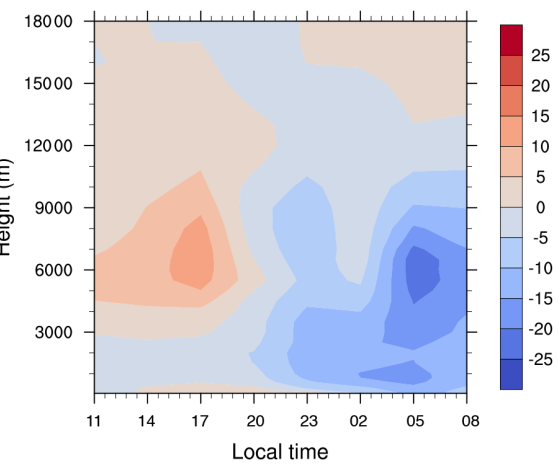

(d) Temperature difference $\left({ }^{\circ} \mathrm{C}\right)$

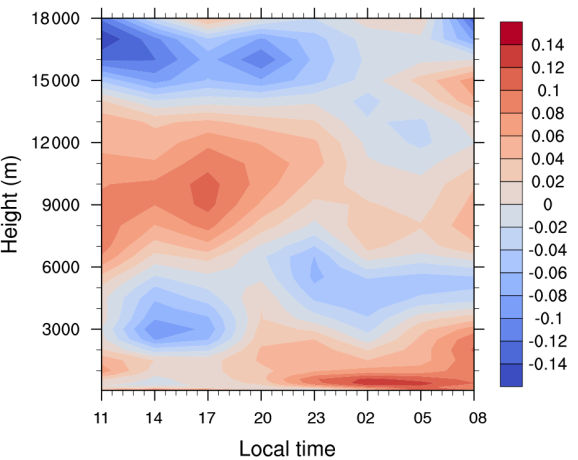

(f) Vertical velocity difference $\left(\mathrm{m} \mathrm{s}^{-1}\right)$

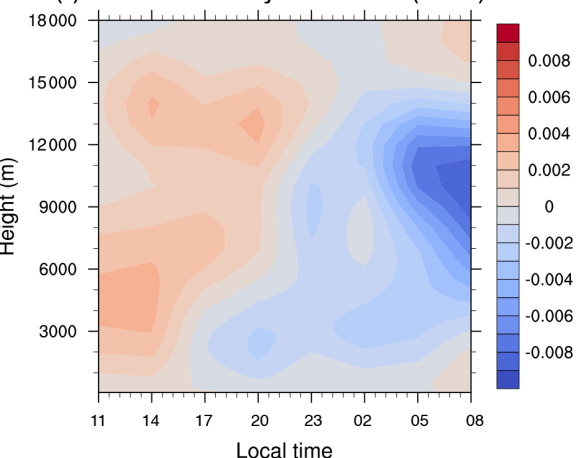

Figure 12. Diurnal evolution of vertical profiles over the Borneo region (r2) in FF for (a) total hydrometeor mixing ratio (mg kg-1), (c) temperature $\left({ }^{\circ} \mathrm{C}\right)$, and (e) vertical velocity $\left(\mathrm{m} \mathrm{s}^{-1}\right)$. Data are averaged all the nocturnal convections. Panels (b), (d), and (f) are the differences between FF and FFBB (FFBB-FF) for each parameter.

simulated. Three convective events of each study region have been selected for in-depth investigation. In addition, statistical analyses have been performed throughout the entire simulation period for each region. We have focused our analyses on two rainfall features: (1) convective precipitation associated with Sumatra squall lines and (2) diurnal rainfall over western Borneo.

We find that fire aerosols lead to an increase in cloud water mass and cloud droplet number concentration among all analyzed cases, as well as a substantial reduction of raindrop number concentration. The influence of fire aerosols on other hydrometeors varies from case to case. Specifically, our results show that fire aerosols can significantly change the quantities of hydrometeors, particularly those involved in cold cloud processes and rainfall of weak convections in either the Sumatra region or the Borneo region. Rainfall intensity is higher in FFBB during the entire convection life cycle in those weak convection cases, and the nighttime rainfall intensity in FFBB is significantly higher than that in FF.

Statistics performed throughout the entire modeled fire season show that the fire aerosols only cause a nearly negligible change $(2 \%-3 \%)$ to the total rainfall of convective systems in both study regions. On the other hand, we notice that fire aerosols can still alter daily maximum and minimum 
(a) Daytime - no fire

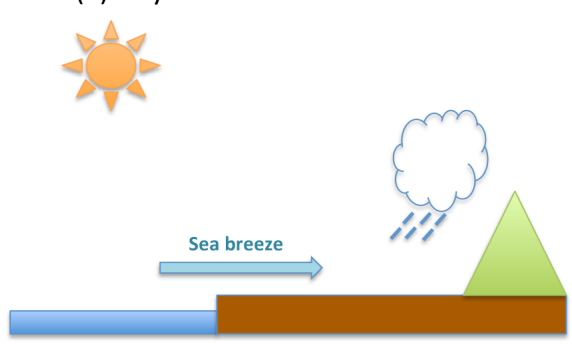

(c) Nighttime - no fire

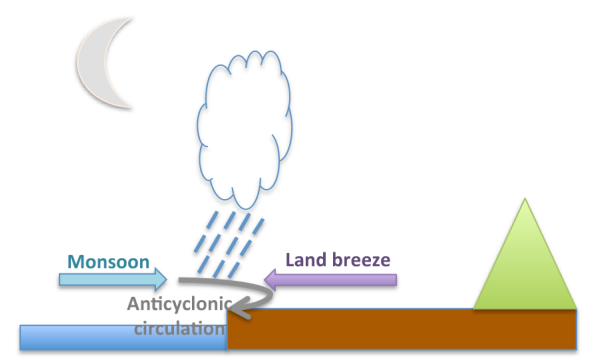

(b) Daytime - fire event

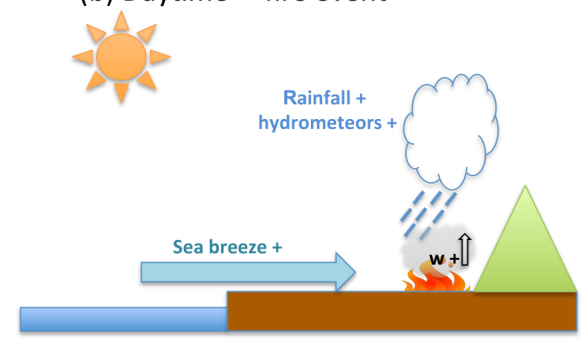

(d) Nighttime - fire event

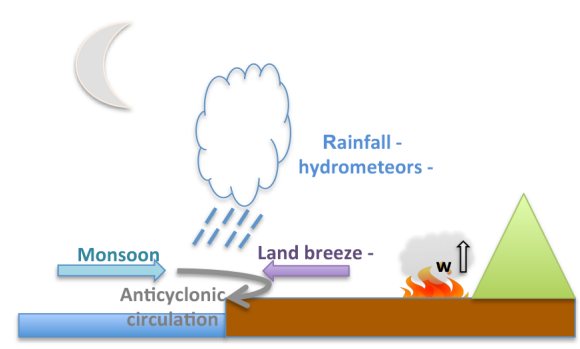

Figure 13. Schematics of diurnal rainfall and convection activity over western Borneo. Panels (a) and (b) illustrate the formation of convection during the daytime without and with a fire event, respectively. Panels (c) and (d) are the same as (a) and (b) but for activity observed at nighttime.

rainfall in some cases. For example, fire aerosols led to an increase in maximum and minimum rainfall intensity in 30 weak convective events in the Sumatra region.

In the Borneo region, biomass burning activities mainly affect the rainfall intensity of nocturnal convection. Because near-surface heating from the absorption of fire aerosols can enhance the prevailing wind from the ocean (sea breeze) during the daytime, the convective rainfall over the western mountain range is higher during the onset stage of the nocturnal convections. At nighttime, the consequence of the above thermodynamic perturbation due to absorbing fire aerosols can further weaken land breeze and surface convergence. Hence, the rainfall intensity of nocturnal convections under the influence of fire aerosols would become weaker by about $9 \%$.

This study has demonstrated how biomass burning activities could affect convective systems over the Maritime Continent by altering cloud microphysics and dynamics. We find the biomass burning activities significantly change the diurnal rainfall intensity, especially those low-level wind patterns associated with the weak westerly (WW) regime, as suggested by Ichikawa and Yasunari (2006). Our results show that neither a single case study nor a simple statistical summary applied to the overall model simulation period without in-depth analyses could reveal the impact of biomass burning aerosols on convections under different windflaw regimes.
Data availability. FINNv1.5 emission data are publicly available from the U.S. National Center for Atmospheric Research (NCAR) website (http://bai.acom.ucar.edu/Data/fire/, National Center for Atmospheric Research, 2020). REAS emission data are provided from National Institute for Environmental Studies in Japan and can be downloaded from https://www.nies.go.jp/REAS/ (REAS, 2020). TRMM and MODIS data are provided from the National Aeronautics and Space Administration (NASA). TRMM data can be obtained from https://pmm.nasa.gov/data-access/ downloads/trmm (NASA, 2020). AOD from MODIS can be obtained from https://doi.org/10.5067/MODIS/MOD08_M3.061 (last access: February 2020). Sounding profiles are supported by University of Wyoming and are publicly available on http://weather.uwyo. edu/upperair/sounding.html (University of Wyoming, 2020). WRFChem-simulated data are available upon request from Hsiang-He Lee (lee1061@1lnl.gov).

Supplement. The supplement related to this article is available online at: https://doi.org/10.5194/acp-20-2533-2020-supplement.

Author contributions. HHL and CW designed the experiments, and HHL carried them out. HHL configured the simulations and analyzed the results. HHL and CW wrote the manuscript.

Competing interests. The authors declare that they have no conflict of interest. 
Acknowledgements. This research was supported by the National Research Foundation Singapore, through the Singapore-MIT Alliance for Research and Technology, an interdisciplinary research program of the Center for Environmental Sensing and Modeling. It was also supported by the U.S. National Science Foundation (AGS-1339264), the U.S. Department of Energy (DE-FG0294ER61937), and L'Agence National de la Recherche (ANR) of France under the "Programme d'Investissements d'Avenir" (ANR18-MPGA-003 EUROACE). The authors would like to acknowledge the NCEP-FNL and NCAR FINN working groups for releasing their data to the research communities and the NCAR WRF development team for providing the numerical model for this study. The computational work for this article was performed using resources of the National Supercomputing Centre, Singapore.

Financial support. This research has been supported by the L'Agence National de la Recherche (ANR) of France (Make-OurPlanet-Great-Again Initiative, ANR-18-MPGA-003 EUROACE grant), the National Research Foundation Singapore (SingaporeMIT Alliance for Research and Technology grant), the U.S. National Science Foundation (grant no. AGS-1339264), and the U.S. Department of Energy (grant no. DE-FG02-94ER61937).

Review statement. This paper was edited by Yun Qian and reviewed by three anonymous referees.

\section{References}

Ackermann, I. J., Hass, H., Memmesheimer, M., Ebel, A., Binkowski, F. S., and Shankar, U.: Modal aerosol dynamics model for Europe: development and first applications, Atmos. Environ., 32, 2981-2999, https://doi.org/10.1016/S13522310(98)00006-5, 1998.

Andreae, M. O. and Gelencsér, A.: Black carbon or brown carbon? The nature of light-absorbing carbonaceous aerosols, Atmos. Chem. Phys., 6, 3131-3148, https://doi.org/10.5194/acp-63131-2006, 2006.

Chang, C.-P., Millard, J. E., and Chen, G. T. J.: Gravitational Character of Cold Surges during Winter MONEX, Mon. Weather Rev., 111, 293-307, https://doi.org/10.1175/15200493(1983)111<0293: gcocsd>2.0.co;2, 1983.

Chang, C.-P., Harr, P. A., and Chen, H.-J.: Synoptic Disturbances over the Equatorial South China Sea and Western Maritime Continent during Boreal Winter, Mon. Weather Rev., 133, 489-503, https://doi.org/10.1175/mwr-2868.1, 2005.

Crippa, P., Castruccio, S., Archer-Nicholls, S., Lebron, G. B., Kuwata, M., Thota, A., Sumin, S., Butt, E., Wiedinmyer, C., and Spracklen, D. V.: Population exposure to hazardous air quality due to the 2015 fires in Equatorial Asia, Scientific Reports, 6, 37074, https://doi.org/10.1038/srep37074, 2016.

Fan, J., Rosenfeld, D., Zhang, Y., Giangrande, S. E., Li, Z., Machado, L. A. T., Martin, S. T., Yang, Y., Wang, J., Artaxo, P., Barbosa, H. M. J., Braga, R. C., Comstock, J. M., Feng, Z., Gao, W., Gomes, H. B., Mei, F., Pöhlker, C., Pöhlker, M. L., Pöschl, U., and de Souza, R. A. F.: Substantial convection and precipi- tation enhancements by ultrafine aerosol particles, Science, 359, 411-418, https://doi.org/10.1126/science.aan8461, 2018.

Frankenberg, E., McKee, D., and Thomas, D.: Health consequences of forest fires in Indonesia, Demography, 42, 109-129, https://doi.org/10.1353/dem.2005.0004, 2005.

Freitas, S. R., Longo, K. M., Chatfield, R., Latham, D., Silva Dias, M. A. F., Andreae, M. O., Prins, E., Santos, J. C., Gielow, R., and Carvalho Jr., J. A.: Including the sub-grid scale plume rise of vegetation fires in low resolution atmospheric transport models, Atmos. Chem. Phys., 7, 3385-3398, https://doi.org/10.5194/acp7-3385-2007, 2007.

Fujii, Y., Iriana, W., Oda, M., Puriwigati, A., Tohno, S., Lestari, P., Mizohata, A., and Huboyo, H. S.: Characteristics of carbonaceous aerosols emitted from peatland fire in Riau, Sumatra, Indonesia, Atmos. Environ., 87, 164-169, https://doi.org/10.1016/j.atmosenv.2014.01.037, 2014.

Ge, C., Wang, J., and Reid, J. S.: Mesoscale modeling of smoke transport over the Southeast Asian Maritime Continent: coupling of smoke direct radiative effect below and above the low-level clouds, Atmos. Chem. Phys., 14, 159-174, https://doi.org/10.5194/acp-14-159-2014, 2014.

Grandey, B. S., Lee, H.-H., and Wang, C.: Radiative effects of interannually varying vs. interannually invariant aerosol emissions from fires, Atmos. Chem. Phys., 16, 14495-14513, https://doi.org/10.5194/acp-16-14495-2016, 2016.

Grell, G. A. and Freitas, S. R.: A scale and aerosol aware stochastic convective parameterization for weather and air quality modeling, Atmos. Chem. Phys., 14, 5233-5250, https://doi.org/10.5194/acp-14-5233-2014, 2014.

Grell, G. A., Peckham, S. E., Schmitz, R., McKeen, S. A., Frost, G., Skamarock, W. C., and Eder, B.: Fully coupled "online" chemistry within the WRF model, Atmos. Environ., 39, 6957-6975, https://doi.org/10.1016/j.atmosenv.2005.04.027, 2005.

Hodzic, A. and Duvel, J. P.: Impact of Biomass Burning Aerosols on the Diurnal Cycle of Convective Clouds and Precipitation Over a Tropical Island, J. Geophys. Res.-Atmos., 123, 1017-1036, https://doi.org/10.1002/2017JD027521, 2017.

Huffman, G. J., Bolvin, D. T., Nelkin, E. J., Wolff, D. B., Adler, R. F., Gu, G., Hong, Y., Bowman, K. P., and Stocker, E. F.: The TRMM Multisatellite Precipitation Analysis (TMPA): Quasi-Global, Multiyear, Combined-Sensor Precipitation Estimates at Fine Scales, J. Hydrometeorol., 8, 38-55, https://doi.org/10.1175/JHM560.1, 2007.

Iacono, M. J., Delamere, J. S., Mlawer, E. J., Shephard, M. W., Clough, S. A., and Collins, W. D.: Radiative forcing by long-lived greenhouse gases: Calculations with the AER radiative transfer models, J. Geophys. Res.-Atmos., 113, D13103, https://doi.org/10.1029/2008JD009944, 2008.

Ichikawa, H. and Yasunari, T.: Time-Space Characteristics of Diurnal Rainfall over Borneo and Surrounding Oceans as Observed by TRMM-PR, J. Climate, 19, 1238-1260, https://doi.org/10.1175/jcli3714.1, 2006.

Jeong, G.-R. and Wang, C.: Climate effects of seasonally varying Biomass Burning emitted Carbonaceous Aerosols (BBCA), Atmos. Chem. Phys., 10, 8373-8389, https://doi.org/10.5194/acp10-8373-2010, 2010.

Jiang, J. H., Su, H., Huang, L., Wang, Y., Massie, S., Zhao, B., Omar, A., and Wang, Z.: Contrasting effects on deep convective 
clouds by different types of aerosols, Nature Commun., 9, 3874, https://doi.org/10.1038/s41467-018-06280-4, 2018.

Koh, T.-Y. and Teo, C.-K.: TOWARD A MESOSCALE OBSERVATION NETWORK IN SOUTHEAST ASIA, B. Am. Meteorol. Soc., 90, 481-488, https://doi.org/10.1175/2008bams2561.1, 2009.

Kunii, O., Kanagawa, S., Yajima, I., Hisamatsu, Y., Yamamura, S., Amagai, T., and Ismail, I. T. S.: The 1997 Haze Disaster in Indonesia: Its Air Quality and Health Effects, Archives of Environmental Health: An International Journal, 57, 16-22, https://doi.org/10.1080/00039890209602912, 2002.

Kurokawa, J., Ohara, T., Morikawa, T., Hanayama, S., JanssensMaenhout, G., Fukui, T., Kawashima, K., and Akimoto, H.: Emissions of air pollutants and greenhouse gases over Asian regions during 2000-2008: Regional Emission inventory in ASia (REAS) version 2, Atmos. Chem. Phys., 13, 11019-11058, https://doi.org/10.5194/acp-13-11019-2013, 2013.

Lee, H.-H., Bar-Or, R. Z., and Wang, C.: Biomass burning aerosols and the low-visibility events in Southeast Asia, Atmos. Chem. Phys., 17, 965-980, https://doi.org/10.5194/acp-17-965-2017, 2017.

Lee, H.-H., Iraqui, O., Gu, Y., Yim, S. H.-L., Chulakadabba, A., Tonks, A. Y.-M., Yang, Z., and Wang, C.: Impacts of air pollutants from fire and non-fire emissions on the regional air quality in Southeast Asia, Atmos. Chem. Phys., 18, 6141-6156, https://doi.org/10.5194/acp-18-6141-2018, 2018.

Lee, H.-H., Iraqui, O., and Wang, C.: The Impact of Future Fuel Consumption on Regional Air Quality in Southeast Asia, Scientific Reports, 9, 2648, https://doi.org/10.1038/s41598-01939131-3, 2019.

Lin, J. C., Matsui, T., Pielke Sr., R. A., and Kummerow, C.: Effects of biomass-burning-derived aerosols on precipitation and clouds in the Amazon Basin: a satellite-based empirical study, J. Geophys. Res.-Atmos., 111, D19204, https://doi.org/10.1029/2005jd006884, 2006.

Lin, N.-H., Tsay, S.-C., Maring, H. B., Yen, M.-C., Sheu, G.-R., Wang, S.-H., Chi, K. H., Chuang, M.-T., Ou-Yang, C.-F., Fu, J. S., Reid, J. S., Lee, C.-T., Wang, L.-C., Wang, J.-L., Hsu, C. N., Sayer, A. M., Holben, B. N., Chu, Y.-C., Nguyen, X. A., Sopajaree, K., Chen, S.-J., Cheng, M.-T., Tsuang, B.-J., Tsai, C.J., Peng, C.-M., Schnell, R. C., Conway, T., Chang, C.-T., Lin, K.-S., Tsai, Y. I., Lee, W.-J., Chang, S.-C., Liu, J.-J., Chiang, W.-L., Huang, S.-J., Lin, T.-H., and Liu, G.-R.: An overview of regional experiments on biomass burning aerosols and related pollutants in Southeast Asia: From BASE-ASIA and the Dongsha Experiment to 7-SEAS, Atmos. Environ., 78, 1-19, https://doi.org/10.1016/j.atmosenv.2013.04.066, 2013.

Lo, J. C. F. and Orton, T.: The general features of tropical Sumatra Squalls, Weather, 71, 175-178, https://doi.org/10.1002/wea.2748, 2016.

Miettinen, J., Shi, C., and Liew, S. C.: Deforestation rates in insular Southeast Asia between 2000 and 2010, Glob. Change Biol., 17, 2261-2270, https://doi.org/10.1111/j.1365-2486.2011.02398.x, 2011.

Mlawer, E. J., Taubman, S. J., Brown, P. D., Iacono, M. J., and Clough, S. A.: Radiative transfer for inhomogeneous atmospheres: RRTM, a validated correlated-k model for the longwave, J. Geophys. Res.-Atmos., 102, 16663-16682, https://doi.org/10.1029/97JD00237, 1997.
Morrison, H., Curry, J. A., and Khvorostyanov, V. I.: A New Double-Moment Microphysics Parameterization for Application in Cloud and Climate Models. Part I: Description, J. Atmos. Sci., 62, 1665-1677, https://doi.org/10.1175/jas3446.1, 2005.

Morrison, H., Thompson, G., and Tatarskii, V.: Impact of Cloud Microphysics on the Development of Trailing Stratiform Precipitation in a Simulated Squall Line: Comparison of One- and Two-Moment Schemes, Mon. Weather Rev., 137, 991-1007, https://doi.org/10.1175/2008mwr2556.1, 2009.

Nakanishi, M. and Niino, H.: Development of an Improved Turbulence Closure Model for the Atmospheric Boundary Layer, J. Meteorol. Soc. Japan. Ser. II, 87, 895-912, https://doi.org/10.2151/jmsj.87.895, 2009.

NASA: TRMM Data Downloads, available at: https://pmm.nasa. gov/data-access/downloads/trmm, last access: February 2020.

National Centers for Atmospheric Research (NCAR): Fire Emission Factors and Emission Inventories, available at: http://bai. acom.ucar.edu/Data/fire/, last access: February 2020.

National Centers for Environmental Prediction, N. W. S. N. U. S. D. o. C.: NCEP FNL Operational Model Global Tropospheric Analyses, continuing from July 1999, https://doi.org/10.5065/D6M043C6, 2000.

Oki, T. and Musiake, K.: Seasonal Change of the Diurnal Cycle of Precipitation over Japan and Malaysia, J. Appl. Meteorol., 33, 1445-1463, https://doi.org/10.1175/15200450(1994)033<1445: scotdc >2.0.co;2, 1994.

Ramanathan, V. and Carmichael, G.: Global and regional climate changes due to black carbon, Nature Geosci., 1, 221-227, 2008.

Ramanathan, V., Crutzen, P. J., Lelieveld, J., Mitra, A. P., Althausen, D., Anderson, J., Andreae, M. O., Cantrell, W., Cass, G. R., Chung, C. E., Clarke, A. D., Coakley, J. A., Collins, W. D., Conant, W. C., Dulac, F., Heintzenberg, J., Heymsfield, A. J., Holben, B., Howell, S., Hudson, J., Jayaraman, A., Kiehl, J. T., Krishnamurti, T. N., Lubin, D., McFarquhar, G., Novakov, T., Ogren, J. A., Podgorny, I. A., Prather, K., Priestley, K., Prospero, J. M., Quinn, P. K., Rajeev, K., Rasch, P., Rupert, S., Sadourny, R., Satheesh, S. K., Shaw, G. E., Sheridan, P., and Valero, F. P. J.: Indian Ocean Experiment: An integrated analysis of the climate forcing and effects of the great Indo-Asian haze, J. Geophys. Res.-Atmos., 106, 28371-28398, https://doi.org/10.1029/2001jd900133, 2001.

Regional Emission inventory in ASia (REAS): https://www.nies.go. jp/REAS/, last access: February 2020.

Rosenfeld, D.: TRMM observed first direct evidence of smoke from forest fires inhibiting rainfall, Geophys. Res. Lett., 26, 31053108, https://doi.org/10.1029/1999g1006066, 1999.

Rosenfeld, D., Lohmann, U., Raga, G. B., O’Dowd, C. D., Kulmala, M., Fuzzi, S., Reissell, A., and Andreae, M. O.: Flood or Drought: How Do Aerosols Affect Precipitation?, Science, 321, 1309-1313, https://doi.org/10.1126/science.1160606, 2008.

Satheesh, S. K. and Ramanathan, V.: Large differences in tropical aerosol forcing at the top of the atmosphere and Earth's surface, Nature, 405, 60-63, https://doi.org/10.1038/35011039, 2000.

Schell, B., Ackermann, I. J., Hass, H., Binkowski, F. S., and Ebel, A.: Modeling the formation of secondary organic aerosol within a comprehensive air quality model system, J. Geophys. Res.Atmos. (1984-2012), 106, 28275-28293, 2001.

Sekiguchi, M., Nakajima, T., Suzuki, K., Kawamoto, K., Higurashi, A., Rosenfeld, D., Sano, I., and Mukai, S.: A study of the direct 
and indirect effects of aerosols using global satellite data sets of aerosol and cloud parameters, J. Geophys. Res.-Atmos., 108, 4699, https://doi.org/10.1029/2002JD003359, 2003.

Shi, H., Jiang, Z., Zhao, B., Li, Z., Chen, Y., Gu, Y., Jiang, J. H., Lee, M., Liou, K.-N., Neu, J. L., Payne, V. H., Su, H., Wang, Y., Witek, M., and Worden, J.: Modeling Study of the Air Quality Impact of Record-Breaking Southern California Wildfires in December 2017, J. Geophys. Res.-Atmos., 124, 6554-6570, https://doi.org/10.1029/2019jd030472, 2019.

Stockwell, W. R., Kirchner, F., Kuhn, M., and Seefeld, S.: A new mechanism for regional atmospheric chemistry modeling, J. Geophys. Res.-Atmos., 102, 25847-25879, https://doi.org/10.1029/97JD00849, 1997.

Taylor, D.: Biomass burning, humans and climate change in Southeast Asia, Biodivers. Conserv., 19, 1025-1042, https://doi.org/10.1007/s10531-009-9756-6, 2010.

Tewari, M., Chen, F., Wang, W., Dudhia, J., LeMone, M. A., Mitchell, K., Ek, M., Gayno, G., Wegiel, J., and Cuenca, R. H.: Implementation and verification of the unified NOAH land surface model in the WRF model, 20th conference on weather analysis and forecasting/16th conference on numerical weather prediction, Seattle, WA, USA, 2004.

Tosca, M. G., Randerson, J. T., and Zender, C. S.: Global impact of smoke aerosols from landscape fires on climate and the Hadley circulation, Atmos. Chem. Phys., 13, 5227-5241, https://doi.org/10.5194/acp-13-5227-2013, 2013.

University of Wyoming: Sounding profiles, available at: http:// weather.uwyo.edu/upperair/sounding.html, last access: February 2020.

Wagner, A., Heinzeller, D., Wagner, S., Rummler, T., and Kunstmann, H.: Explicit Convection and Scale-Aware Cumulus Parameterizations: High-Resolution Simulations over Areas of Different Topography in Germany, Mon. Weather Rev., 146, 19251944, https://doi.org/10.1175/mwr-d-17-0238.1, 2018.
Wang, C.: A modeling study on the climate impacts of black carbon aerosols, J. Geophys. Res.-Atmos., 109, D03106, https://doi.org/10.1029/2003JD004084, 2004.

Wang, C.: A modeling study of the response of tropical deep convection to the increase of cloud condensation nuclei concentration: 1. Dynamics and microphysics, J. Geophys. Res.-Atmos., 110, D21211, https://doi.org/10.1029/2004JD005720, 2005.

Wiedinmyer, C., Akagi, S. K., Yokelson, R. J., Emmons, L. K., AlSaadi, J. A., Orlando, J. J., and Soja, A. J.: The Fire INventory from NCAR (FINN): a high resolution global model to estimate the emissions from open burning, Geosci. Model Dev., 4, 625641, https://doi.org/10.5194/gmd-4-625-2011, 2011.

Wu, P., Hara, M., Hamada, J.-I., Yamanaka, M. D., and Kimura, F.: Why a Large Amount of Rain Falls over the Sea in the Vicinity of Western Sumatra Island during Nighttime, J. Appl. Meteorol. Climat., 48, 1345-1361, https://doi.org/10.1175/2009jamc2052.1, 2009.

Wu, R., Wen, Z., and He, Z.: ENSO Contribution to Aerosol Variations over the Maritime Continent and the Western North Pacific during 2000-10, J. Climate, 26, 6541-6560, https://doi.org/10.1175/JCLI-D-12-00253.1, 2013.

Yi, L. and Lim, H.: Semi-Idealized COAMPS ${ }^{\circledR} *$ Simulations of Sumatra Squall Lines: the Role of Boundary Forcing, Solid Earth Ocean Sci. Atmos. Sci., 9, https://doi.org/10.1142/9789812708946_0009, 2006.

Zhang, Y., Fan, J., Logan, T., Li, Z., and Homeyer, C. R.: Wildfire impact on environmental thermodynamics and severe convective storms, Geophys. Res. Lett., 46, 10082-10093, https://doi.org/10.1029/2019gl084534, 2019.

Zhao, B., Gu, Y., Liou, K.-N., Wang, Y., Liu, X., Huang, L., Jiang, J. H., and Su, H.: Type-Dependent Responses of Ice Cloud Properties to Aerosols From Satellite Retrievals, Geophys. Res. Lett., 45, 3297-3306, https://doi.org/10.1002/2018g1077261, 2018. 